\title{
MODIFICAÇÃO DA CASCATA E TAXA LIPOLÍTICA DO TECIDO ADIPOSO DE OVELHAS LACTANTES TRATADAS COM SOMATOTROPINA BOVINA
}

\author{
MARINA HOJAIJ CARVALHO
}

Dissertação apresentada à Escola Superior de Agricultura "Luiz de Queiroz", Universidade de São Paulo, para obtenção do título de Mestre em Agronomia, Área de Concentração: Ciência Animal e Pastagens.

PIR A C I C A B A

Estado de São Paulo - Brasil

Março - 2003 


\title{
MODIFICAÇÃO DA CASCATA E TAXA LIPOLÍTICA DO TECIDO ADIPOSO DE OVELHAS LACTANTES TRATADAS COM SOMATOTROPINA BOVINA
}

\author{
MARINA HOJAIJ CARVALHO
}

Médica Veterinária

Orientador: Prof. Dr. EDUARDO FRANCISQUINE DELGADO

Dissertação apresentada à Escola Superior de Agricultura "Luiz de Queiroz", Universidade de São Paulo, para obtenção do título de Mestre em Agronomia, Área de Concentração: Ciência Animal e Pastagens.

PIRACICABA

Estado de São Paulo - Brasil

Março-2003 


\title{
Dados Internacionais de Catalogação na Publicação (CIP)
} DIVISÃO DE BIBLIOTECA E DOCUMENTAÇÃO - ESALQ/USP

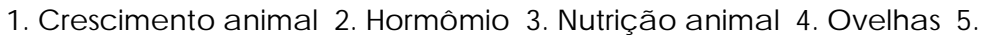 \\ Tecido de animal I. Título \\ CDD 636.3
}

"Permitida a cópia total ou parcial deste documento, desde que citada a fonte - $\mathrm{O}$ autor" 
"Sorte é a opinião do indolente sobre o êxito de quem se esforça"

Anônimo

Em primeiro lugar a Deus, com Ele tudo é possível.

Aos meus pais, Mariza e Rafael, pelo imenso amor e carinho que sempre conseguiram me fazer sentir, dando forças para continuar a minha caminhada.

Aos maravilhosos irmãos, Marília, Mônica, Maristela e Rafael (incluem-se os cunhados e cunhada) que em todo momento se fizeram presentes, mesmo com a tão grande distância em que a vida nos colocou, nunca deixaram de cuidar da irmã caçula!

Às minhas queridas amigas de república, Erika, Vivi, Dezza, Maria Alice, Dani, Letícia e Bel, que nunca deixaram faltar àamizade e o companheirismo que se aprende a ter durante toda a graduação e que não devem ser perdidos jamais!!

Aos Professores Dr. Delphim da Graça Macoris e Dr. Alexandre Vaz Pires pelos conselhos que me ajudaram a escolher este rumo durante um difícil período de escolhas e decisões.

DEDICO. 


\section{AGRADECIMENTOS}

Ao Prof. Dr. Eduardo Francisquine Delgado, pela orientação e sabedoria que me proporcionaram novos conhecimentos para seguir em frente;

Ao Prof. Dr. Dante Pazzanese Lanna pela imensa satisfação de podermos ter trabalhado juntos, e principalmente, por todos os ensinamentos e oportunidades proporcionados em todos os momentos;

Ao Prof. Dr. Raul Machado Neto, pelos bons exemplos de vida e confiança que me foi dada;

À Prof ${ }^{a}$ Dra. Ivanete Susin, por permitir que o projeto se tornasse realidade, concedendo o espaço e proporcionando ainda, grandes colaborações juntamente ao Prof. Dr. Alexandre Vaz Pires;

A ESALQ/USP e ao Departamento de Zootecnia e sua comissão de Pós Graduação pelo apoio na realização do projeto;

Aos grandes amigos Patrícia, Vicente, Carla, Rosana, Tamy e Carlos pela grande ajuda e acima de tudo, a amizade que fizemos; 
Aos amigos do Laboratório de Nutrição e Crescimento Animal:

Adriana, Alexandre, Amanda, André, Andréa, Dimas, Elaine, Eric, Fê, Juliano, Liana, Marcelo, Marco Antônio, Rodrigo, Oscar, Sérgio, Tuka e Ana, por conseguirem transformar dificuldades em conquistas e trabalho em alegria;

Também ao Sr. Laureano e a D. Eva que me acolheram em momentos difíceis, me dando todo o carinho e a atenção de verdadeiros pais;

Aos estagiários e funcionários do Clube de Práticas Zootécnicas (CPZ), por sempre estarem presentes não deixando que nada faltasse.

Ao Laboratório de Biologia Molecular de Plantas do Departamento de Genética da ESALQ - USP.

\author{
À Cláudia Cristina Paro de Paz pelo grande auxílio nas análises \\ estatísticas.
}

E ao CNPq pela bolsa de estudos concedida. 


\section{SUMÁRIO}

LISTA DE FIGURAS................................................................ viii

LISTA DE TABELAS.......................................................................

LISTA DE ABREVIATURAS.............................................................. xi

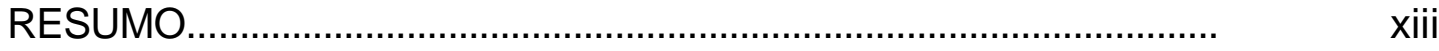

SUMMARY ..........................................................................

1 INTRODUÇÃO

2 REVISÃO DE LITERATURA...........................................................

2.1 Somatotropina e a regulação de nutrientes.................................... 3

2.2 Efeito da ST exógena e endógena na mobilização de gordura..............................................................................

2.3 Cascata lipolítica e hormônios............................................................ 8

2.3.1 Adenosina e Catecolaminas................................................... 8

2.3.2 Receptores e tradução do sinal hormonal........................... 10

2.3.3 ST, sistema $\beta$ adrenérgico e adenosina............................... 12

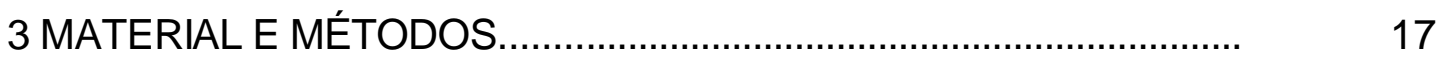

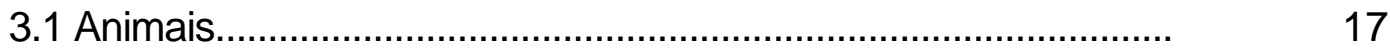

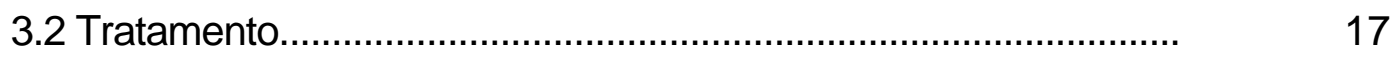

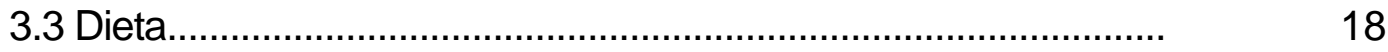




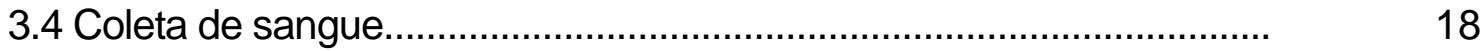

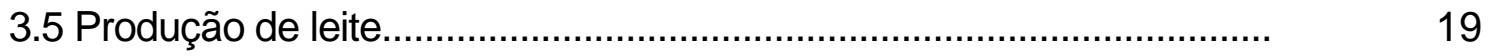

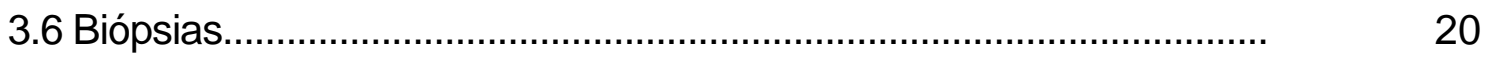

3.6.1 Preparo do tecido para incubação............................................. 20

3.6.2 Incubações de curta duração....................................................... 21

3.6.3 Coleta de meio de incubação de curta duração.............................. 21

3.7 Determinação de ácidos graxos não esterificados................................. 22

3.8 Determinação de IGF-I no plasma........................................................ 22

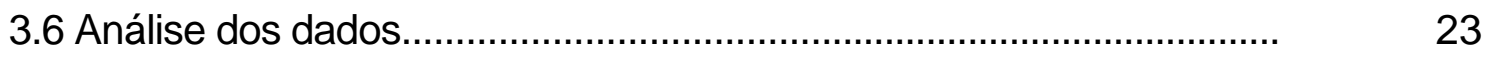

4 RESULTADOS E DISCUSSÃO.......................................................... 24

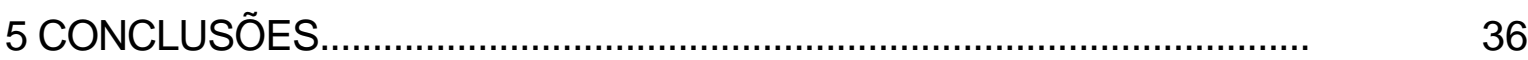

REFERÊNCIAS BIBLIOGRÁFICAS.............................................................. 37

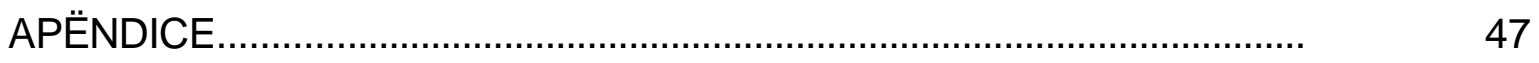




\section{LISTA DE FIGURAS}

Página

1 Mecanismo de ação da adenosina e sua relação com o mecanismo de ação das catecolaminas e norepinefrina

2 Cronograma de coleta de sangue e aplicação de bST exógena ou

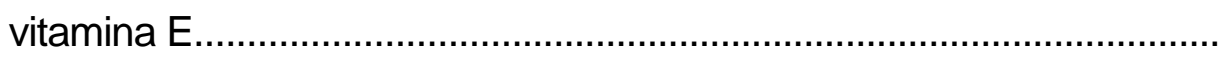

3 Médias de produção de leite tomadas pelo método da pesagem do cordeiro

4 Liberação de AGNE no plasma sangüíneo das ovelhas dos 3 grupo sem diferentes datas pós parto para os animais lactantes

5 Inibição da lipólise. Pelo análogo da ADA, N6- fenilisopropiladenosina (PIA), estimulada por isoproterenol em cultura de tecido adiposo de ovelhas em diferentes estados fisiológicos

6 Abertura do flanco direito para retirada do tecido adiposo (biópsia)............

7 Sutura do flanco direito (término da biópsia).

8 Preparação do tecido adiposo para incubação. 
9 Coleta de amostra de meio de lipólise durante a cultura do tecido 47 adiposo.

10 Colocação da atmosfera de ar $\left(95 \% \mathrm{O}_{2}\right.$ e $\left.5 \% \mathrm{CO}_{2}\right)$ no frasco de 48 cintilação durante a incubação. 


\section{LISTA DE TABELAS}

Página

1 Composição da dieta fornecida às ovelhas.

18

2 Variação do ganho de peso médio $(\mathrm{kg})$ em relação ao peso ao parto das ovelhas verificado durante o período da lactação no experimento em diferentes períodos.

24

3 Médias de pesos e ganho de pesos diário dos cordeiros pesados em 2 períodos a partir da data do parto....................

4 Concentrações de IGF-I (ng/mL) no plasma sangüíneo em

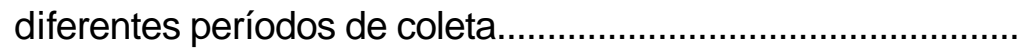

5 Efeitos do tratamento crônico com somatotropina bovina in vivo nas taxas de lipólise in vitro dos explantes de tecido adiposo do omento de ovelhas................................................... 


\section{LISTA DE ABREVIATURAS}

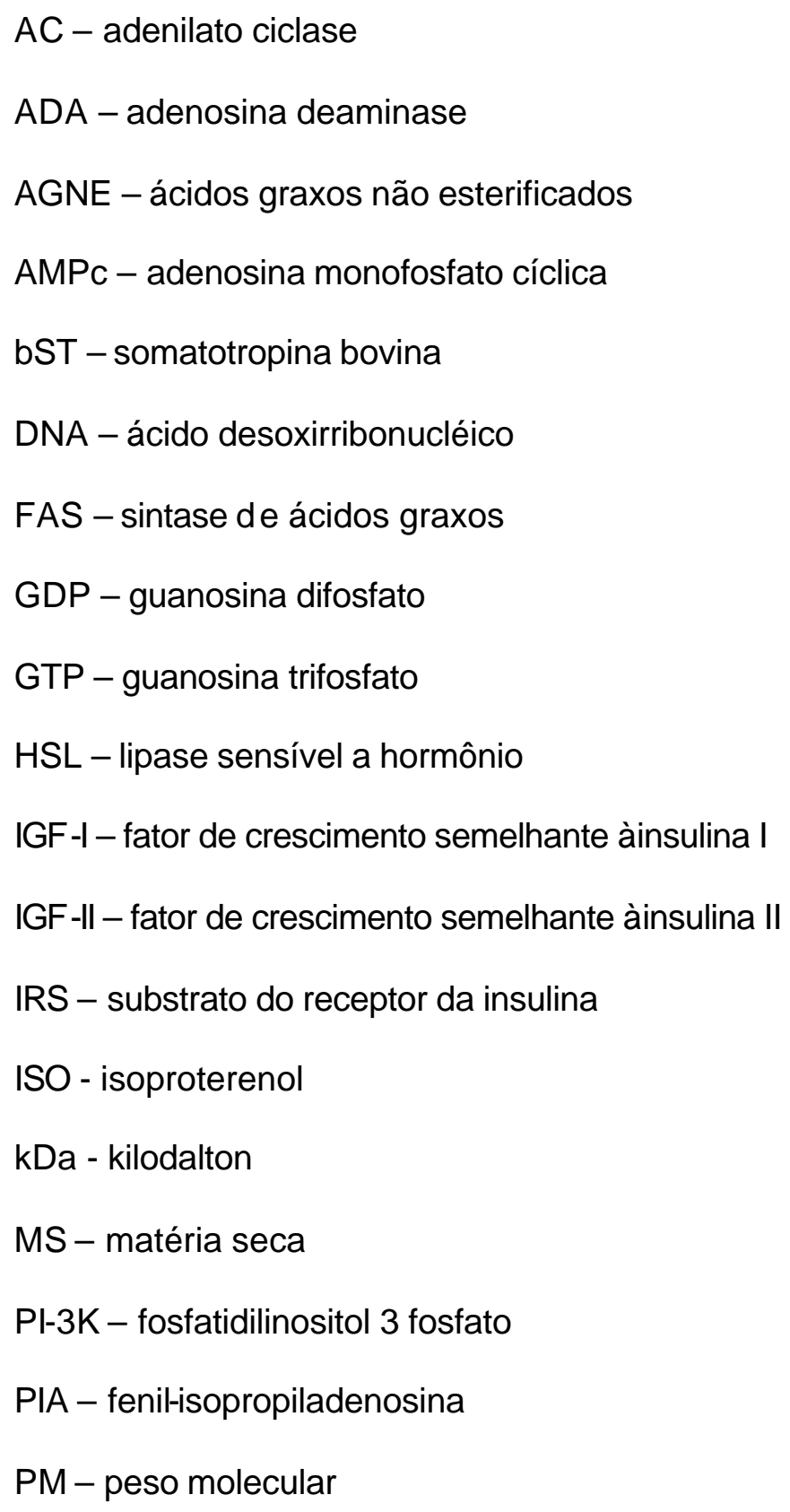


RNAm - ácido ribonucléico mensageiro

ST - somatotropina 


\title{
MODIFICAÇÃO DA RESPOSTA LIPOLÍTICA ESTIMULADA POR $\beta$ - ADRENÉRGICOS NO TECIDO ADIPOSO DE OVELHAS LACTANTES TRATADAS COM SOMATOTROPINA BOVINA.
}

\author{
Autora: MARINA HOJAIJ CARVALHO \\ Orientador: Prof. Dr. EDUARDO FRANCISQUINE DELGADO
}

\section{RESUMO}

Foram utilizadas 24 ovelhas da raça Santa Inês para coleta de tecido adiposo, sendo 16 lactantes e 8 secas. Oito ovelhas lactantes foram tratadas in vivo com bST (160 mg, em duas doses em intervalo de 14 dias) iniciando a injeção subcutânea de hormônio no $13^{\circ}$ dia de lactação, sendo que os animais restantes receberam somente vitamina $\mathrm{E}$. Outros 8 animais encontravam-se em período seco, para que fosse verificada também a diferença das taxas lipolíticas em diferentes estados fisiológicos. Foi verificada a hipótese de que ocorra uma atuação da ST através de mudança na resposta do sistema antilipolítico da proteína Gi ligada a receptores da adenosina.

O tratamento com ST exógena aumentou o ganho de peso das ovelhas lactantes $(P<0,05)$ e também o peso dos cordeiros oriundos do grupo tratado ao final do período experimental, no entanto, não foi verificado aumento na produção de leite.

As concentrações de AGNE diminuíram no decorrer da lactação para os

dois grupos de ovelhas lactantes, chegando no $36^{\circ}$ dia de lactação a 
concentrações similares ao do grupo de ovelhas secas. A concentração de IGFI sérico das ovelhas aumentou após tratamento com bST, sendo 8 dias após a segunda dose do hormônio (36 dias de lactação) superior à concentração observada para ovelhas secas.

A lactação não teve influência na lipólise basal entre os diferentes estados fisiológicos. Houve um aumento significativo $(P<0,01)$ da taxa lipolítica do tecido adiposo quando estimulada por $\beta$ adrenérgico (ISO) para animais em quaisquer dos estados fisiológicos. Todavia, a taxa estimulada por ISO foi significativamente $(P<0,01)$ mais elevada no tecido das ovelhas tratadas com bST. Na presença de ADA, ocorreu um aumento da taxa em relação à basal, mas não ultrapassou àquela estimulada por isoproterenol. $O$ estímulo lipolítico pela eliminação de adenosina no meio através da ADA apresentou-se significativamente $(P<0,01)$ mais elevado para ovelhas lactantes, sendo este efeito amenizado pelo tratamento com bST. O uso do análogo da adenosina PIA quando colocado no meio de cultura do tecido que foi tratado in vivocom bST teve seu efeito diminuído.

Os resultados indicam um aumento da taxa lipolítica em resposta a agonista $\beta$-adrenérgico no tecido adiposo do omento de ovelhas lactantes tratadas com bST in vivo, bem como confirmam a hipótese de diminuição da ação inibitória da adenosina na cascata lipolítica naquele tecido. 


\title{
EFFECT OF PHYSIOLOGICAL STATE AND SOMATOTROPIN ON THE RESPONSE TO LIPOLYTIC AND ANTILIPOLYTIC SIGNALLING IN OVINE ADIPOSE TISSUE.
}

\author{
Author: MARINA HOJAIJ CARVALHO \\ Adviser: Prof. Dr. EDUARDO FRANCISQUINE DELGADO \\ SUMMARY
}

Bovine somatotropin (bST) treatment in vivo alters adipose tissue metabolism by enhancing lipolytic response to adrenergic agonists. We examined the impact of bST and lactation on basal and stimulated lipolytic rates with isoproterenol (ISO; $10^{-5} \mathrm{nM}$ ), adenosine deaminase (ADA; $0.75 \mathrm{U} / \mathrm{mL}$ ), ISO plus ADA in short-term (2h) incubations of ovine adipose tissue. The antilipolytic effect of phenylisopropyladenosine (PIA; non-hydrolyzable adenosine analog) was evaluated at various concentrations $(0.5,1.5,3,100 \mathrm{nM})$. Sixteen lactating Santa Ines ewes were randomly assigned to two groups. They received two s.c. injections, with a 14 day interval, starting at $d 13$ postpartum with either bST $(160 \mathrm{mg}$ ) or Vitamin E (control). Eight similar nonlactating ewes received vitamin E. Omental adipose tissue biopsies were taken on $d 8$ after the second bST or vitamin injection.

The performance of weight and milk production were taken. The serum IGF-I was analyzed. The lipolytic rate was determined by NEFA release in serum and media as $\mu$ Eq of oleic acid. $2 \mathrm{~h}^{-1} \mathrm{~g}^{-1}$ tissue. 
Basal lipolytic rates did not change with lactation or with bST treatment in vivo $(P>0,05)$. ISO stimulated lipolytic rate increased compared to basal and was higher for the adipose tissue from lactating ewes treated with bST $(P<0,01)$.The lipolytic rate for adipose incubated with ADA was higher than basal for lactating ewes, with the greater response for the control. The ADA treated tissue from lactating ewes receiving bST showed intermediate lipolytic rates. Maximum lipolytic rate with ISO+ADA was also higher for lactating ewes treated with bST $(P<0.01)$, and there was no difference between lactating and nonlactating ewes. The PIA effects were evaluated by the inhibition of ISO+ADA lipolysis, and adipose tissue from lactating ewes treated with bST showed a reduced response to PIA. The results demonstrate that in vivo somatotropin treatment increases maximal lipolytic rates stimulated by adrenergic agonist and decreases the antilipolytic effect of PIA in omental adipose tissue in ewes. 


\section{INTRODUÇÃO}

O grande desafio da ciência e da tecnologia será proporcionar viabilidade e qualidade ao crescimento da população mundial, a qual poderá duplicar nos próximos 40 anos (NRC, 1994). Tem sido estimado, que para suprir as exigências nutricionais humanas necessárias para este período, terá que ser produzida uma quantidade de alimento igual àquela produzida por toda a história da humanidade. Para isto, os pesquisadores têm se empenhado no desenvolvimento e aprimoramento de novas alternativas que aumentem a eficiência de produção de alimentos (Bauman, 1999).

No âmbito da produção animal, a somatotropina (ST), ou hormônio do crescimento, apresenta-se como uma das alternativas de grande impacto na eficiência de produção e qualidade do alimento. $O$ aumento da síntese de tecido muscular, em detrimento do tecido adiposo causado pela ST em suínos e bovinos, tecnologia já explorada comercialmente, tem se tornado característica cada vez mais importante frente às recomendações de instituições ligadas à saúde humana para diminuição de consumo de gordura de origem animal (NAS, 1988).

Em se tratando de leite, aumentos na ordem de $20 \%$ na produção têm sido relatados sem alterar 0 aporte de energia líquida exigida por vacas lactantes de alta produção tratadas com ST bovina (Lanna et al., 1996). Resultado este de uma alteração coordenada no metabolismo de diversos tecidos, especialmente do tecido adiposo (Bauman et al., 1989).

As alterações metabólicas ditadas pela ST são caracterizadas pela sinalização através de eventos chave para a mudança do estado fisiológico 
visando adequar as alterações nas exigências dos diversos tecidos e órgãos de maneira a atender a reprodução, sobrevivência e crescimento de forma eficiente.

O ciclo de prenhez, lactação e desmama tem um grande efeito no metabolismo de lipídios no tecido adiposo, onde as reservas são normalmente acumuladas durante a primeira fase do ciclo (Watt et al., 1991). Durante a transição do estado fisiológico que ocorre com a parição, o metabolismo do tecido adiposo é alterado de maneira a suportar a partição de nutrientes para a glândula mamária visando à síntese de leite (Bauman \& Currie, 1980). Estas mudanças são estabelecidas pelo aumento da ST em animais lactantes (Vernon, 1980; Bauman \& Elliot, 1983).

Portanto, o objetivo deste projeto foi ampliar o conhecimento sobre o efeito da ST exógena in vivo na taxa lipolítica através da interação de sua ação regulatória positiva sobre a mobilização de ácidos graxos pela cascata do sistema $\beta$ adrenérgico agonista e negativa pela adenosina utilizando incubações in vitro de tecido adiposo de animais tratados com ST, e ainda, elucidar estas alterações promovidas pela ST no tecido adiposo ditadas pela fase inicial de lactação em ovelhas. 


\section{REVISÃO DE LITERATURA}

\subsection{Somatotropina e a regulação da utilização de nutrientes}

Há mais de 80 anos, pesquisadores demonstraram a presença de uma substância produzida pela hipófise anterior que aumentava o crescimento de ratos (Evans \& Long, 1921). Foi documentado que o efeito do tratamento com este extrato, aumentava o ganho de peso da massa muscular e reduzia a gordura corporal. Em seguida a esse trabalho, Stricker \& Grueter (1928), citado por Bauman \& Vernon (1993), observaram que esses extratos também aumentavam a produção de leite em ratas e cabras. Segundo a revisão de Bauman \& Vernon (1993) foi assim que a substância recebeu, então, o nome de "somatotropina", palavra de origem grega que significa "crescimento do tecido".

No início da década de 1980, com a revolução proporcionada pelo avanço da ciência molecular e celular, tornou-se possível à produção de proteínas pela técnica do DNA recombinante, permitindo a obtenção de quantidades significativas de ST recombinante que proporcionaria trabalhos

pioneiros com somatotropina bovina recombinante em vacas pelo grupo de pesquisa de D. E. Bauman.

A ST é um hormônio protéico, também denominado hormônio do crescimento, sintetizado pela hipófise anterior e diretamente regulado por dois peptídeos: 1) somatocrinina, fator liberador do hormônio do crescimento e 2) somatostatina, que inibe esta liberação. Em geral, contém de 190 a 191 aminoácidos. A molécula de ST bovina e a suína, para citar duas espécies de interesse zootécnico, possuem um alto grau de homologia na estrutura primária da proteína $(90 \%)$, fato que não ocorre entre todas as espécies. Como um 
exemplo, tome-se a seqüência de aminoácidos do hormônio bovino que difere em $35 \%$ comparada à observada na espécie humana, fazendo com que seus efeitos biológicos sejam normalmente limitados à espécie que sintetiza o hormônio. Esta informação é de grande relevância para a saúde, pois o tratamento com ST não transfere esta proteína para os alimentos originados dos animais tratados com atividade hormonal em humanos (Etherton \& Bauman, 1998). Por esta razão a ST é citada na literatura como sendo "espécie específica", embora Bauman e Vernon (1993) considerem mais preciso referirse à ela como "espécie limitada". Uma exceção é a atividade da somatotropina bovina (bST) em ovinos, que, segundo Bauman e Vernon (1993), possui tamanho grau de homologia que confere ação hormonal nas duas espécies em questão.

Estudos utilizando bovinos (Etherton et al., 1987, Sechen et al., 1990), suínos (Etherton \& Bauman, 1998), ovinos (Vernon et al., 1991, Watt et al., 1991) e ratos (Vernon et al.,1987), mostraram efeitos biológicos da ST diretos ou indiretos sobre os tecidos, podendo os mesmos serem somatogênicos ou metabólicos. O efeito somatogênico ocorre pela estimulação da proliferação celular e o metabólico inclui a ação da ST para coordenar o metabolismo, envolvendo uma variedade de tecidos e classes de nutrientes como carboidratos, proteínas, lipídios e minerais. Efeitos indiretos são mediados pelo IGF-I e IGF-II que são fatores de crescimento dependentes de ST (Rechler \& Nissley, 1990; Bauman \& Vernon, 1993).

Em 1989, Bauman et al. propuseram que a ST bovina teria efeito em longo prazo através da modulação de respostas do tecido adiposo aos hormônios que controlam os mecanismos de ajuste instantâneo das condições normais do meio interno denominados homeostáticos. Em 1990, Sechen et al. mostraram claramente este efeito através do aumento da liberação de glicerol após infusões com hormônios lipolíticos (catecolaminas) em bovinos tratados com ST por 12 dias. 
Em estudos iniciais do efeito da ST exógena sobre o metabolismo de vacas em lactação, verificou-se que o estado nutricional do animal antes do início do tratamento dita a forma e magnitude de resposta. O aumento da mobilização de reservas de gordura, verificado pela maior concentração de açidos graxos não esterificados e glicerol no sangue, é a adaptação mais importante em vacas lactantes com balanço energético negativo (Bauman et al., 1988; Boisclair et al., 1997), e a diminuição na síntese de lipídios é a resposta predominante em vacas com balanço positivo de energia. A energia despendida para mantença ou a eficiência parcial para síntese de leite não é alterada pelo uso da ST (Sechen et al., 1989).

Portanto, mesmo antes da elucidação das modificações, a conseqüência metabólica da ação da ST no tecido adiposo era reconhecida pela disponibilização de nutrientes não mais aproveitados ou mesmo mobilizados do tecido adiposo para outros tecidos e orgãos, como a glândula mamária (Etherton et al., 1987).

Sendo um fator homeorrético, isto é, atuando no rearranjo de sinais e resposta dos tecidos a diversos fatores reguladores das condições normais do meio interno bem como, diretamente sobre as funções metabólicas, a ST age indiretamente na partição de nutrientes pelo organismo. Desta maneira promove de forma orquestrada o aporte hormonal e nutricional que privilegia a produção de leite durante a lactação e de carne magra durante o crescimento (Sechen et al., 1989, Houseknecht et al., 1994, Houseknecht et al., 1995a; Etherton \& Bauman, 1998). Entre os processos, ela exerce uma ação antagônica sobre a resposta à insulina e um efeito negativo sobre a atividade de enzimas reguladoras da síntese de lipídios (Lanna et al., 1995). 


\subsection{Efeito da ST exógena e endógena na mobilização de gordura}

A função primordial do tecido adiposo é armazenar energia na forma de ácidos graxos e glicerol, principalmente para ocasiões quando a ingestão de nutrientes da dieta não é suficiente para suprir as exigências do animal. Durante o início da lactação, a maior parte desta energia armazenada é utilizada pela glândula mamária. Uma função secundária é sintetizar ácidos graxos para sustentar a secreção de gordura no leite (McNamara, 1991). O tecido adiposo dos mamíferos é regulado de maneira estrita permitindo uma adaptação para suportar os estados fisiológicos de prenhez e lactação a fim de superar períodos de déficit de energia e gordura garantindo a boa nutrição da prole (Pond, 1984).

A partição de nutrientes para os vários tecidos envolvem dois tipos de regulação: a homeostase e a homeorrese. O controle homeostático envolve a manutenção do equilíbrio fisiológico, ou seja, a constância do ambiente interno do organismo. A homeorrese é o segundo tipo de controle na partição de nutrientes. Podendo ser definida como as alterações coordenadas no metabolismo dos tecidos necessárias para suportar mudanças no estado fisiológico (Bauman \& Currie, 1980).

Sendo assim, o tecido adiposo é um importante alvo para o controle homeorrético do metabolismo pela ST. Estratégias maternas para suprir as exigências do feto por glucose e aminoácidos não incluem somente mudanças no metabolismo de carboidratos e proteínas, mas também no metabolismo de lipídios. Para diversas espécies de mamíferos está estabelecida a ocorrência de um acúmulo de reservas de lipídios durante o início da gestação para ser utilizado ao final da mesma e na lactação. No início da gestação, o feto pode não obter vantagem direta dos lipídios mobilizados pela mãe (Bell, 1994).

Em 1966, Fain \& Scow verificaram que durante a transição do final da gestação para o início da lactação ocorriam alterações na capacidade de 
síntese de lipídios no tecido adiposo. Lanna \& Bauman (1999) demonstraram que essas alterações são decorrentes de uma diminuição no uso de nutrientes para deposição de reserva corporal, processo concomitante com um aumento na habilidade de mobilizar as reservas existentes na forma de gordura. A demanda adicional por nutrientes determinada pela alta atividade sintética e presença de quantidade significativa de nutrientes nas secreções lácteas da glândula mamária são as maiores causas da alteração deste metabolismo (Vernon et al., 1995).

No tecido adiposo, a lipogênese é menor em animais lactantes que em animais prenhes, verificando-se no período pré-parto uma intensificação da lipólise (McNamara \& Hillers, 1986). Esta atividade metabólica é maximizada no tecido adiposo em várias espécies, incluindo ratos, camundongos e ovinos durante o início da lactação (Vernon \& Flint, 1984). Especialmente em ovinos, o início da mobilização de lipídios pode ocorrer muitas semanas antes do parto, principalmente quando são ovelhas de dois ou mais cordeiros (Robinson et al., 1978).

Durante a primeira semana de lactação, as vias lipolíticas apresentam maior fluxo, podendo-se verificar isto através do aumento da lipólise basal e atividade da lipase sensível a hormônio in vitro, e ainda aumento das concentrações de ácidos graxos e glicerol no sangue (Sidhu e Emery, 1972).

De maneira semelhante ao que acontece na transição do estado fisiológico seco para o lactante, o tratamento com ST exógena ocasiona alterações importantes no tecido adiposo, permitindo que uma maior quantidade de nutrientes seja disponibilizada para suprir as exigências para produção de leite da glândula mamária de vacas de alta produção ou para crescimento do tecido muscular (Lanna et al., 1995; Lanna e Bauman, 1999).

As exigências por nutrientes pela glândula mamária para produção de leite podem exceder à demanda nutri cional de todo o restante do organismo (Bauman e Elliot, 1983). Em determinado momento essas exigências podem 
ser supridas pelo aumento da ingestão de alimentos, sendo que em outros momentos, este mecanismo torna-se insuficiente verificando-se a mobilização de reservas de gorduras e minerais, bem como em casos extremos o uso de proteína corporal pelo animal.

O controle da lipólise durante a lactação demorou a ser elucidado. Anteriormente, os resultados apontavam para um aumento do tamanho do adipócito; mais recentemente, sabe-se que outros mecanismos concorrem para o aumento da lipólise (Vernon \& Finley, 1985).

\subsection{Cascata lipolítica e hormônios}

\subsubsection{Adenosina e Catecolaminas}

Os primeiros estudos sobre o efeito da adenosina sobre o metabolismo do tecido adiposo foram há mais de 40 anos, feitos por Dole em 1961. A adenosina é um hormônio produzido por vários tecidos, tem efeitos em diversos sistemas como o sistema cardiovascular (potente vasodilatador) (Berne et al., 1983) e ainda sobre metabolismo do tecido adiposo, tendo ação autócrina ou parácrina via ação da enzima 5'-nucleotidase, que se localiza na membrana plasmática com locais de exposição no meio extracelular (Arch e Newsholme, 1978).

A concentração de adenosina no tecido adiposo é de 0,5 a $1 \mathrm{nmol} / \mathrm{g} \mathrm{em}$ humanos e ratos (Ohisalo et al.,1987), podendo variar muito em resposta a diferentes estímulos, como por exemplo, no caso de isquemia que pode aumentar esta concentração em até 10 vezes (Arch e Newsholme, 1978, citado por Vernon,1984). Esta sustância parece agir primordialmente como um antagonista da norepinefrina. A resposta à adenosina é também alterada quando o animal muda de estado fisiológico, como da prenhez para a lactação (Vernon, 1984). 
As catecolaminas são aminas com ação hormonal derivadas de processo de hidroxilação da tirosina. As principais catecolaminas são a dopamina, epinefrina e norepinefrina. Estas aminas e adenosina possuem um mecanismo de ação muito similar (Figura 1).

Alguns estudos in vitro, sugeriam que ocorre uma menor resposta desse sistema em tecido adiposo de ratos (Vernon, 1980). Todavia, diversos trabalhos demonstraram que as catecolaminas podem aumentar a taxa de lipólise in vivo (Thompson, 1986) e in vitro (Vernon e Finley, 1985, McNamara, 1988) em várias espécies de animais.

Outro fator que pode também interferir na resposta do tecido é o tamanho da célula, o que acaba dificultando as comparações das respostas em situações que ocorrem alterações no tamanho das células como acontece no período da lactação (Vernon e Flint, 1984).

A prenhez e a lactação alteram a resposta do tecido adiposo aos efeitos lipolíticos das catecolaminas em bovinos (Yang e Baldwin, 1937) e em ovinos (Vernon e Finley, 1985). Esta mudança com o $\beta$ adrenérgico, isoproterenol, foi verificada pelo aumento evidente na sensibilidade do tecido no final da gestação e início da lactação em ovinos (Guesnet et al., 1987). Essas diferenças podem ser devido à resposta realçada do sistema $\alpha$ receptor durante a lactação (Vernon e Sasaki, 1991). O mecanismo responsável por este efeito lipolítico aumentado ainda não foi bem elucidado, mas não parece estar relacionado apenas ao aumento no número de receptores $\beta$ adrenérgico tanto para bovinos como para ovinos.

Em 1983, Vernon et al. demonstraram que em ratas em lactação, o efeito antilipolítico da adenosina era aumentado, o que evitaria uma perda excessiva das reservas de lipídios no início da lactação preservando a fêmea para priorizar o processo reprodutivo. Subseqüentemente, foi visto que o mesmo acontecia no tecido adiposo de ovelhas em lactação (Vernon \& Finley, 1985). Estudos preliminares sugeriram que a resposta máxima do sistema antilipolítico 
$\alpha_{2}$ adrenérgico era aumentada em adipócitos de ovelhas em lactação, mas em dois experimentos subseqüentes não foi encontrada a mesma resposta. $O$ número de receptores $\mathrm{A} 1$ dos adipócitos de ovelhas em lactação foi aumentado. Contudo, estudos mais recentes indicam promover mudanças na tradução do sinal. Inesperadamente, uma aparente atividade máxima da adenilato ciclase parece ser diminuída pela lactação em ratas, enquanto a atividade da Gi é aumentada em algumas vias durante a lactação em ovinos (Watt et al., 1991). A mudança na atividade da $\mathrm{Gi}$ pode ocorrer pelo aumento da resposta a adenosina e agentes $\alpha_{2}$ adrenérgicos.

Os estudos descritos mostram que a mudança do estado fisiológico pode causar uma série complexa de modificações na tradução do sinal. Outro fator que ocorre em ratas em lactação, é uma diminuição na atividade da fosfodiesterase (enzima que remove AMPc da célula) observado por Aitchison et al. em 1982.

\subsubsection{Receptores e tradução do sinal hormonal}

Os receptores $\beta$ adrenérgicos já foram classificados em 2 subtipos: $\beta 1$ e $\beta 2$ (Lefkowitz \& Caron, 1987). Atualmente, existem caracterizados três receptores $\beta$, estando presentes em tecido adiposo os subtipos $\beta 1$ e $\beta 3$. Os receptores $\alpha$ adrenérgicos, igualmente aos $\beta$, também são divididos em 2 subtipos: $\alpha 1$ e $\alpha 2$. $0 \alpha 1$ está associado ao fosfatidilinositol e não regula a atividade do sistema adenilato ciclase. Por outro lado, o receptor $\alpha 2$ é uma glicoproteína $(\mathrm{PM}=65 \mathrm{kDa}$ ) diretamente ligado ao sistema $\mathrm{AC}$, onde sua ativação inibe a unidade catalítica da AC (Geirschik \& Jakobs, 1988). A seqüência de aminoácidos indica sete domínios inseridos na membrana plasmática e muitas regiões homólogas aos $\beta$ receptores.

Os receptores para adenosina podem ser classificados em 3 subtipos denominados A1, A2 e P. O A1 e A2 são membros da família de receptores T7R que interagem com as proteínas $G$ e forma primeiramente descritos em 
preparações de membrana de cérebro, tecido adiposo e fígado (Van Calker et al., 1978; Londos et al., 1980). O receptor $\mathrm{P}$ reconhece a adenosina, e está localizado no interior da membrana plasmática e diretamente inibe AC pela interação com a subunidade catalítica da enzima (Daly, 1985). No entanto, todos os 3 subtipos tem sido descritos no tecido adiposo de ratos, o $\mathrm{P}$ tem uma baixa afinidade pela adenosina, o A2 aparece fracamente ligado a AC ou mesmo está presente em baixas quantidades (Garcia-Sainz and Torner, 1985). Então, somente o receptor A1 mostra ser fisiologicamente relevante para o metabolismo do tecido adiposo (Houseknecht et al., 1994).

O subtipo Ra ou A2 está associado ao estímulo da atividade da AC através da proteína Gs. O subtipo Ri ou A1 interage com a proteína Gi diminuindo a atividade da AC (Schwabe, 1984). No caso do tecido adiposo causa inibição, apesar dos adipócitos posuírem os dois tipos de receptores (Fain \& Malbon, 1979; Garcia-Sainz and Torner, 1985)

Como já visto, os receptores $\alpha 2, \beta 1$ e 3 e Ri estão ligados ao sistema da $A C$ e sob uma ativação estimulatória hormonal, através das proteínas $G$ regulam a atividade da $A C$ alterando a taxa de síntese do $A M P c$ responsável pela ativação da proteína quinase $A$ ou proteína quinase dependente de AMPc (PKA), que por sua vez está envolvida na fosforilação de enzimas intracelulares. Esta modificação covalente (fosforilação) resulta na conversão da lipase sensível a hormônio (HSL) em sua forma ativa, resultando na hidrólise de triglicerídios (Brownsey et al., 1979). A proteína quinase $A$ pode também fosforilar a acetil CoA carboxilase, reduzindo sua atividade e diminuindo a lipogênese (Brownsey e Hardie, 1980; Garcia-Sainz e Fain, 1982).

Como ocorre em diversos sistemas regulatórios biológicos, a atividade dos sítios catalíticos (2) da Adenilato Ciclase (AC) está sob um controle duplo (positivo e negativo). A ligação com isoproterenol (agonista $\beta 1$ e $\beta 2$ ) ou epinefrina (Epi, agonista $\alpha$ e $\beta$ adrenérgico) faz com que o receptor $\beta$ 
adrenérgico promova a substituição do GDP pelo GTP na Gs (proteína G estimulatória). A hipótese mais aceita indica que a dissociação da $\alpha$ s ativada pela ligação ao GTP, ao interagir com a AC aumente a taxa de produção de AMPc, sendo o nível deste mensageiro secundário (intracelular) o principal regulador da mobilização de gordura nos adipócitos (Robinson et al., 1971).

\subsubsection{ST, sistema $\beta$-adrenérgico e adenosina}

De maneira simplificada, o modelo de regulação da lipólise nas células adiposas, ocorre pelo estímulo de hormônios como as catecolaminas, glucagônio e adrenocorticotrópicos que ativam uma enzima multiregulada, a adenilato ciclase $(\mathrm{AC})$, formando em resposta a adenosina monofosfato cíclica (AMPc), que por sua vez estimula a proteína quinase $A$, a qual ativa a lipase sensível a hormônio (HSL). No modelo descrito, o AMPc é o mensageiro secundário na ativação de lipólise em células adiposas.

Todos os receptores que interagem com o sistema cascata para modular níveis intracelulares de um segundo mensageiro (AMPC), o fazem por intermédio da família das proteínas $G$ (Milligan et al., 1988). As proteínas $G$ correspondem a uma super família com a capacidade de se ligar ao GTP/GDP. Cada proteína $G$ possui uma guanosina ligada à sub -unidade $\alpha$, que por sua vez está complexada com as sub-unidades $\beta$ e $\gamma$. Sua ativação leva a uma modificação de conformação e troca de GDP por GTP com posterior dissociação da GTP- $\alpha$ de $\beta$ e $\gamma$, iniciando uma cascata sinalizadora. Esta subunidade $\alpha$ é responsável pela regulação da atividade da adenilato ciclase (Neer, 1995; Taussie \& Gilman, 1995). A sub-unidade $\alpha$ dissociada transmite sinais estimulatórios chamados de $\alpha$, os que causam inibição, são chamados de $\alpha i$ (Vernon \& Sasaki, 1991).

Os fatores responsáveis por todas essas modificações têm sido bem estudados, mas há uma evidência de que a ST implica em mudanças na resposta máxima do sistema $\beta$ adrenérgico. Estudos detalhados por Bauman et 
al., (1988) e Sechen et al., (1989) sugerem que a resposta máxima, e não a sensibilidade do tecido, é alterada. Culturas de tecido adiposo de ovinos por 48 horas com ST aumenta o número de $\beta$ receptores, mas não há efeito no número de receptores $\alpha_{2}$ ou $\mathrm{A} 1$. A exposição deste tecido a ST, in vitro, aumenta a resposta máxima do efeito lipolítico do isoproterenol e também a sensibilidade a este agonista adrenérgico (Watt et al., 1990). A ST também apresenta um pequeno efeito inibitório sobre o efeito antilipolítico da adenosina (Vernon et al., 1987).

Lanna et al. $(1994,1995)$ demonstraram que os primeiros efeitos da ST sobre a lipólise eram causados por uma redução na resposta do tecido adiposo a adenosina. Este nucleosídeo foi identificado como fator antilipolítico, que apresenta ação autócrina e parácrina ligando-se a receptores de membrana (A1R) que tem como transdutor de sinal a proteína ligante ao GTP (Gi) que, como indicado pelo nome, inibe a atividade da adenilato ciclase (AC) (Honnor et al., 1985; Bauman \& Vernon, 1993; Vernon et al., 1994; Etherton \& Bauman, 1998), suprimindo a produção de AMPc (Schwabe et al., 1973). Já os receptores de $\beta$-adrenérgicos ( $\left.B_{A R}\right)$ acoplam-se a $G$ s, estimulando a adenilato ciclase (Houseknecht \& Bauman, 1994).

A preparação do tecido adiposo para estudos in vitro produz grandes quantidades de adenosina endógena que acaba por ocupar todos os receptores viáveis (Bruns, 1988), por isso esta adenosina endógena, presente em incubações de tecido adiposo deve ser transformada em inosina, um composto que não apresenta efeito sobre a lipólise, esta transformação é feita pela enzima adenosina deaminase (Berne, 1986). A adição desta enzima determina um aumento limitado na taxa de lipólise.

Um análogo da adenosina particularmente útil para estudos da lipólise in vitro é o $\mathrm{N}^{6}$-fenilisopropiladenosina (PIA) que se liga ao receptor $A_{1}$ da adenosina com alta afinidade, mas não é metabolizado pela adenosina deaminase (Lanna et al., 1995). Lanna e et al. (1992), utilizando vacas em 
lactação, verificaram que o tratamento crônico com ST in vivo diminui o efeito antilipolítico deste análogo em tecido adiposo de bovinos in vitro e também em ratos (Vernon et al., 1987; Lanna et al.,1992; Doris et al., 1994).

Este aumento é ainda realçado quando é adicionado o $\beta$-adrenérgico agonista (e.g., isoproterenol) em animais ou tecidos tratados com ST (Doris et al., 1996), verificado também em outros trabalhos utilizando tecido adiposo de ovinos (Watt et al., 1991; Vernon et al., 1991), bovinos (Houseknetch et al., 1995 a e b) e ainda ratas em lactação que tiveram a lipogênese reduzida (Vernon et al., 1987). Entretanto, o tratamento com ST exógena em ratas lactando, não alterou taxa de lipólise estimulada por $\beta$-adrenérgico quando testada na presença de adenosina deaminase (Vernon et al., 1987; Vernon e Finley, 1988).

Outra via de ação da ST acontece através da diminuição da sensibilidade do tecido adiposo à insulina (Lanna et al. , 1995) devido ao mecanismo que envolve a redução da sintetase de ácidos graxos (FAS) (Etherton \& Bauman, 1998). Estudos conduzidos por diversos pesquisadores com ST in vitro não observaram alteração no número de receptores de insulina, como mostram os resultados obtidos por Thirone et al. (1997). Estes últimos não observaram alterações na abundância ou nível de autofosforilação dos receptores de insulina no fígado de ratos. Entretanto, Castro et al. (2001), trabalhando também com tecido de ratos, observaram uma queda nas quantidades dos substratos do receptor da insulina (IRS-1 e IRS-3), bem como na associação com o fosfoinositol 3fosfato (PF3K) quando o explante de tecido adiposo foi submetido ao tratamento com ST in vitro.

Após o tratamento com ST, o efeito antilipolítico da adenosina foi reduzido em ratas lactantes (Vernon et al., 1987) e em cultura de tecido adiposo de ovelhas em lactação (Vernon et al., 1991; Bauman e Vernon, 1993; Etherton e Bauman, 1998). No entanto, em condições similares, não ocorreu alteração 
no número de receptores para adenosina no tecido adiposo (Watt et al., 1991; Doris et al., 1994; Houseknecht et al., 1995b; Lanna et al., 1995).

Os possíveis mecanismos envolvem mudanças nas afinidades das ligações ou no número dos receptores de adenosina, e/ou na quantidade disponível de sub-unidades $\alpha, \beta$ e $\gamma$ de proteína $G$ que se ligam a receptores de adenosina.

Delgado et al. (2000), utilizando tecido adiposo de vacas em período seco, verificaram que a quantidade de RNAm da Gi2 $\alpha$ não apresentou diferenças significativas em culturas de tecido de longa duração tratado ou não com ST. Resultados estes, que corroboram com Houseknecht e Bauman (1997) que, utilizando os mesmos tratamentos, não verificaram diferenças nas quantidades de proteína Gi no tecido adiposo. Entretanto, estes pesquisadores observaram uma mudança na funcionalidade da proteína $G$ (capacidade de ligar a GTP) após o tratamento com ST.

Em bovinos e ovinos, a menor funcionalidade da proteína Gi tem sido apontada como causa da maior lipólise no tecido adiposo de animais recebendo tratamento com ST (Lanna et al., 1995; Doris et al., 1997; Houseknecht e Bauman, 1997).

Outra hipótese de modificação da cascata inibitória surge com a observação de que o tratamento in vitro com ST pode modificar a distribuição da Gi2 $\alpha$, levando a uma maior associação com membranas de baixa densidade, como reportado por Yip e Goodman (1999). Esta redistribuição pode trazer, segundo os pesquisadores, uma menor disponibilidade da proteína na membrana plasmática, que reduziria a resposta ao sinal antilipolítico da adenosina.

Assim, a ação da ST em animais adultos resultaria em uma maior taxa de lipólise envolvendo a resposta lipolítica a catecolaminas que está, em grande parte, relacionada ao decréscimo do bloqueio causado pela inibição da lipólise via mudanças mudanças na proteína $\mathrm{G}_{\mathrm{i}}$ (Bauman, 1999). 


\section{MECANISMO DE AÇÃO DA ADENOSINA}

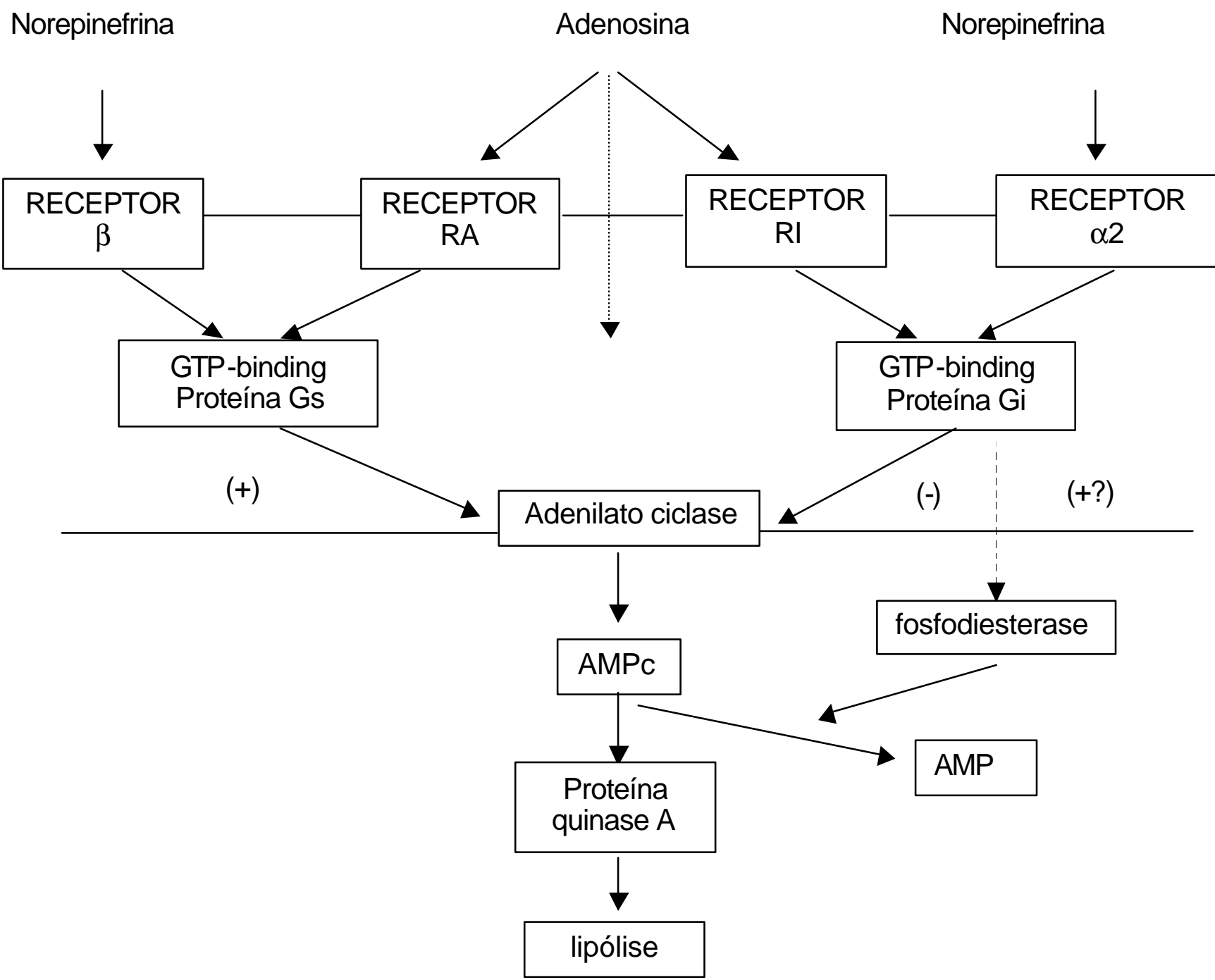

Figura 1- Mecanismo de ação da adenosina e sua elação com o mecanismo de ação das catecolaminas e norepinefrina. Sinais de + ou - significam efeitos estimulatórios ou inibitórios das proteínas Gs ou Gi, respectivamente, na atividade da adenilato ciclase (AC). Linhas pontilhadas indicam interações. GTP = guanina trifosfato (Adaptado de Vernon et al., 1991). 


\section{MATERIAL E MÉTODOS}

O período experimental de campo foi desenvolvido no Departamento de Zootecnia, Sistema Intensivo de Produção de Ovinos e Caprinos (SIPOC) da ESALQ - USP situada no município de Piracicaba, Estado de São Paulo no período de setembro a dezembro do ano de 2001. O restante do experimento e as análises laboratoriais foram realizadas no Laboratório de Nutrição e Crescimento Animal (LNCA) pertencente ao mesmo departamento.

\subsection{Animais}

Foram utilizadas 24 ovelhas $(49,08 \pm 2,65 \mathrm{~kg}$ peso vivo médio) da raça Santa Inês, multíparas, com idade entre três e cinco anos. Alojadas em baias coletivas (8 animais/baia) para cada um dos 3 tratamentos: 1) 8 animais lactantes designados ao tratamento com bST (Boostin®) que era diluído em vitamina $E$ para uma concentração de $80 \mathrm{mg} / \mathrm{mL}$, 2) 8 fêmeas também lactantes, receberam somente a vitamina $E$ (Monovin E), 3) 8 ovelhas em período seco também receberam doses de vitamina $\mathrm{E}$.

\subsection{Tratamento}

Os animais ao $14^{\circ}$ dia de lactação receberam a $1^{\text {a }}$ dose de bST ou vitamina $\mathrm{E}$ e uma $2^{\mathrm{a}}$ dose dos respectivos tratamentos foi injetada no $28^{\circ}$ dia de lactação, alternando-se os lados das aplicações. Um total de dois $\mathrm{mL}$ (dose total do hormônio foi de $160 \mathrm{mg} /$ animal em cada aplicação) foi injetado por via subcutânea na região da cauda. $O$ grupo seco recebia as doses de vitamina $E$ na mesma data dos animais lactantes.

\subsection{Dieta}

Os animais foram alimentados ad libitum, duas vezes ao dia (6h e 18h) com uma ração total que continha capim Napier (Pennicetum purpureum) fresco 
picado, misturado ao concentrado descrito na tabela 1, com proporção de $70 \%$ volumoso e $30 \%$ de concentrado na MS.

O consumo de alimentos por baia foi ajustado diariamente, através da medição da quantidade de alimento ofertado e das sobras retiradas.

Tabela 1. Composição da dieta fornecida às ovelhas.

\begin{tabular}{lc}
\hline \multicolumn{1}{c}{ Ingredientes } & Quantidade (\% MS) $^{1}$ \\
\hline Concentrado & 30,00 \\
Milho grão & 17,60 \\
Farelo de algodão & 9,02 \\
Uréia & 1,12 \\
$\quad$ Mistura Mineral & 2,26 \\
Capim Nappier & 70,00 \\
Composição química & \\
$\quad$ Proteína Bruta & 13,80 \\
$\quad$ NDT & \\
\hline 1= quilogramas de matéria seca & 61,80 \\
$2=$ nutrientes digestíveis totais estimado pelo programa RLM
\end{tabular}

\subsection{Coleta de sangue}

Foram feitas três coletas de sangue da veia jugular dos animais conforme o cronograma abaixo (Figura 2). As fêmeas eram pesadas a cada semana para controle do peso durante o período de experimento. 
Lactação (dias)

\begin{tabular}{|c|c|c|c|c|c|}
\hline Parto & $12^{\circ} \mathrm{dia}$ & $14^{\circ} \mathrm{dia}$ & $17^{\circ} \mathrm{dia}$ & $28^{\circ} \mathrm{dia}$ & $36^{\circ}$ dia \\
\hline & $\perp$ & $\perp$ & $I$ & $I$ & 1 \\
\hline $\begin{array}{l}\text { Pesagem } \\
\text { das fêmeas }\end{array}$ & $\begin{array}{l}1^{\mathrm{a}} \text { coleta } \\
\text { de sangue }\end{array}$ & $\begin{array}{l}1^{\mathrm{a}} \text { dose de } \\
\text { bST ou } \\
\text { vitamina } \mathrm{E}\end{array}$ & $\begin{array}{l}2^{\mathrm{a}} \text { coleta } \\
\text { de sangue }\end{array}$ & $\begin{array}{l}2^{\mathrm{a}} \text { dose de } \\
\text { bST ou } \\
\text { vitamina } \mathrm{E}\end{array}$ & $\begin{array}{l}\text { Biópsia e } 3^{a} \\
\text { coleta de } \\
\text { sangue }\end{array}$ \\
\hline
\end{tabular}

Figura 2 - Cronograma de coleta de sangue e aplicação de bST exógena ou vitamina E.

Após a coleta, o sangue era levado ao laboratório, centrifugado por cinco minutos a $5.000 \mathrm{xg}$ (Eppendorf $\AA$ 5804R) e imediatamente o plasma era acondicionado e congelado a $-20{ }^{\circ} \mathrm{C}$ para posterior determinação da concentração de ácidos graxos não esterificados (AGNE) e IGF-I.

\subsection{Produção de leite}

A produção média de leite das fêmeas foi estimada a cada 14 dias após data do parto pelo método de pesagem do cordeiro antes e após a mamada conforme metodologia de Alencar et al. (1988) com algumas modificações. A prole era separada das respectivas mães e presa, onde permanecia por três horas sem acesso a comida ou água. No momento da mamada, os mesmos eram pesados e soltos junto à mães, nesse período os animais eram monitorados para que não houvesse ingestão de nenhum outro alimento sólido ou líquido para então serem novamente pesados e presos. Este procedimento era repetido quatro vezes ao dia, totalizando um acompanhamento de 12 horas. 


\subsection{Biópsias}

Os explantes de tecido adiposo foram obtidos por biópsia nos animais, sendo estes imobilizados e preparados para uma microcirurgia asséptica. Foi feito um bloqueio anestésico local infiltrativo em "L" com a base paralela à coluna vertebral descendo em direção ao flanco. Uma incisão de 5 a $10 \mathrm{~cm}$ era feita neste local e um explante de tecido adiposo abdominal era removido com auxílio de pinças e tesouras. A sutura da incisão foi feita com pontos "Cushing" utilizando-se categute cromado 2 e a sutura de pele com dois pontos simples separados (quando necessário, era colocado um antibiótico tópico no local). Foi feito o uso de um tratamento sistêmico preventivo utilizando-se um Pentabiótico (Fort Dodge $\AA^{\circledR}$ ) por via intramuscular por três dias. Os explantes de tecido adiposo abdominal depois de retirados, foram lavados e transferidos imediatamente para uma solução salina $(0,15 \mathrm{M} \mathrm{NaCl}), \mathrm{pH} 7,4$ contendo $25 \mathrm{mM}$ HEPES (Sigma Chemical Co.) à temperatura de $37^{\circ} \mathrm{C}$. Estas amostras foram transferidas ao laboratório em um tempo de 5 a 10 minutos para a preparação dos explantes, sendo uma parte do tecido acondicionada em frascos e congeladaà $-80^{\circ} \mathrm{C}$ para quantificação da proteína Gi $\alpha 2$.

\subsubsection{Preparação do tecido para incubação}

As amostras foram mantidas a $37{ }^{\circ} \mathrm{C}$ e $\mathrm{pH} 7,4$ sob placa aquecida enquanto os explantes individuais de aproximadamente $30-40 \mathrm{mg}$ foram preparados com o auxílio de tesouras e bisturi. Em seguida os explantes foram pré-incubados por 15 minutos, em solução tampão de Krebs-Ringer com bicarbonato (KRB) contendo 1,27 mM cálcio, $25 \mathrm{mM}$ HEPES, 5,6 mM de glicose e $3 \%$ de albumina bovina (fração $V$, livre de ácidos graxos; Sigma Chemical). Após a pré-incubação, o tecido foi removido, drenado em papel filtro, pesado e 
transferido para frascos de incubação contendo $1,75 \mathrm{~mL}$ do meio $\mathrm{KRB}$ descrito anteriormente, doravante denominado meio de lipólise.

\subsubsection{Incubações de curta duração}

Para determinação da lipólise eram colocados dois explantes $(30 \mathrm{mg}$ cada em média) em cada frasco de incubação, alocados em triplicatas aleatoriamente para cada animal em um banho-maria com agitação a $37^{\circ} \mathrm{C}$, foram incubados por três horas em $1,75 \mathrm{~mL}$ de meio de lipólise com bicarbonato e HEPES em atmosfera de $95 \% \mathrm{O}_{2}$ e $5 \% \mathrm{CO}_{2}$ com diferentes tratamentos in vitro:

1. controle (lipólise basal)

2. Estimulado por $\beta$-adrenérgico (isoproterenol $10^{-5} \mathrm{M}$ )

3. Estimulado por $\beta$-adrenérgico (isoproterenol $10^{-5} \mathrm{M}$ ) + adenosina deaminase $(0,75 \mathrm{U} / \mathrm{mL})$

4. Estimulado por $\beta$-adrenérgico (isoproterenol $10^{-5} \mathrm{M}$ ) + adenosina deaminase $(0,75 \mathrm{U} / \mathrm{mL})$ e inibido por doses crescentes de $N^{6}$ fenil-isopropiladenosina (PIA) (0,5 nM, 1,5 nM, 3,0 nM e $100 \mathrm{nM})$.

A adenosina deaminase (ADA) (Calbiochem 116880) foi preparada pela diluição em água para concentração de $0,75 \mathrm{U} / \mathrm{mL}$ e passou por diálise em membrana (Spectra/Por Membrane MWCO: 15000) em água UHQ a $8^{\circ} \mathrm{C}$ por 12 horas. A resposta antilipolítica do tecido àadenosina foi estudada no tratamento 4 pela adição de um análogo não hidrolizado por ADA, o PIA (Sigma P4532).

\subsubsection{Coleta de meio de incubação de curta duração}

Imediatamente após os explantes terem sido colocados no frasco, era retirada uma alíquota de $200 \mu \mathrm{L}$ do meio de lipólise, chamada de tempo 0 . Outras duas coletas de $200 \mu \mathrm{L}$ eram repetidas após duas e três horas de incubação. As amostras eram guardadas em frascos "eppendorfs" e 
acondicionadas a $-20{ }^{\circ} \mathrm{C}$ para posterior determinação de ácidos graxos não esterificados (AGNE).

\subsection{Determinação de ácidos graxos não esterificados}

Para avaliar o efeito do bST sobre a taxa de lipólise foi utilizado o "kit" NEFAc (Wako 994-75409E) com algumas modificações.

Para as primeiras medidas foram utilizadas amostras do meio de lipólise retiradas nos tempos 0,2 e 3 horas de incubação. As análises feitas para 0 tempo 0 apresentaram concentrações muito próximas de um limite mínimo de deteç̧ão para presença de AGNE. As concentrações no meio cresceram em taxas similares entre 0 e 2 horas, e entre 2 e 3 horas. Ficou determinado então, que seria analisado somente o tempo de 2 horas e tomado o tempo 0 como tendo uma concentração igual a $0 \mu \mathrm{Eq}$ de ácido oléico.grama de tecido adiposo${ }^{1} .2$ horas $^{-1}$.

Ainda para reduzir custos com o uso do kit comercial, foram diminuídas as quantidades dos reagentes. Ficou determinado que poderia ser utilizado em placa de Elisa com 96 poços, $10 \mu \mathrm{L}$ de amostra, $50 \mu \mathrm{L}$ do reagente $\mathrm{A}, 100 \mu \mathrm{L}$ do reagente $B$ e a leitura feita em espectrofotômetro de placa (Spectramax Molecullar Devices) a $540 \mathrm{~nm}$. As amostras eram de plasma e também do meio de cultura. Os resultados foram expressos em $\mu$ mol. $L^{-1}$ para o plasma e $\mu E q$ de ácido oléico.grama de tecido adiposo ${ }^{-1} .2$ horas $^{-1}$ para o meio de cultura.

\subsection{Determinação de IGF-I no plasma}

As determinações foram realizadas fazendo-se a dosagem no plasma sangüíneo por ensaio imunoradiométrico pós-extração medindo-se a concentração de IGF-I (somatomedina C) (Daughaday \& Rotwein, 1989; Baxter et al., 1989). Os resultados foram obtidos pelo Laboratório de Análises Clínicas Gastão Fleury, localizado na cidade de São Paulo, sob responsabilidade do médico Prof. Dr. José Gilberto H. Vieira. 


\subsection{Análise de dados}

O delineamento foi inteiramente casualizado, com 8 animais por tratamento, sendo 3 tratamentos in vivo. Para as análises de desempenho (peso das ovelhas, peso dos cordeiros e produção de leite) e dos teores plasmáticos de AGNE e IGF-I foram utilizados os procedimentos de modelos lineares gerais (GLM; SAS, 1999-2001) e de modelos lineares mistos (MIXED; SAS, 1999-2001) com medidas repetidas no tempo. Para os teores de AGNE no meio de lipólise, o delineamento foi inteiramente casualizado em parcelas subdivididas, sendo a parcela os tratamentos in vivo e as subparcelas os 8 tratamentos in vitro. Foram feitas duas análises separadas. A primeira com 0 objetivo de verificar as diferenças entre os tratamentos in vitro: basal, ISO, ADA E ISO+ADA e sua interação com os tratamentos in vivo. A segunda análise dos teores de AGNE no meio de lipólise foi realizada para identificar a resposta dos tecidos estimulados por $\beta$ adrenégicos + ADA e do efeito antilipolítico de PIA em doses crescentes. Neste caso utilizou-se o dado com transformação para raiz quadrada e as diferenças entre médias de tratamentos foi verificada por Tukey. 


\section{Resultados e Discussão}

Foram analisados dados de desempenho das ovelhas no período experimental quanto à produção de leite e variação do peso, bem como o ganho de peso dos cordeiros.

Houve um ganho de peso significativo das ovelhas no início da lactação $(P<0,01)$. A partir do dia 7 não houve alteração significativa $(P>0,05)$ no peso até 21 dias pós-parto, sendo que nas pesagens aos 28 e 36 dias observou-se primeiramente um aumento e em seguida uma perda de peso $(P<0,05)$, respectivamente. No que se refere ao ganho de peso das ovelhas, houve um efeito positivo $(P=0,06)$ do tratamento com bST verificado durante todo o período experimental (Tabela 2). Este efeito pode ser verificado pela manutenção do ganho de peso daqueles animais até os 21 dias de lactação. Enquanto que os animais controle apresentaram uma tendência àqueda de peso neste mesmo período.

Tabela 2. Variação do ganho de peso médio $(\mathrm{kg})$ em relação ao peso ao parto das ovelhas verificado durante período da lactação no experimento.

\begin{tabular}{cccccc}
\hline $\begin{array}{c}\text { Tratamento } \\
\text { in vivo }\end{array}$ & 7 & 14 & 21 & 28 & 36 \\
\hline bST & $+4,08(3,3)$ & $+5,13(4,1)$ & $+5,08(4,2)$ & $+6,33(4,4)$ & $+4,55(4,80)$ \\
Controle & $+4,92(2,2)$ & $+4,26(2,6)$ & $+3,65(4,6)$ & $+4,9(4,9)$ & $+3,51(4,5)$ \\
\hline \multicolumn{6}{c}{ Valores entre parênteses indicam desvio padrão da média. }
\end{tabular}


Os cordeiros também foram pesados em períodos diferentes, e o tratamento das ovelhas com bST fez com que seus cordeiros apresentassem maior peso $(\mathrm{P}<0,05)$ ao final do experimento (Tabela 3$)$.

Tabela 3. Médias de pesos e ganho de pesos diários dos cordeiros pesados em 2 períodos a partir da data do parto.

\begin{tabular}{lccc}
\hline Tratamento & Controle & bST & Probabilidade \\
\hline Peso $(\mathrm{kg})$ aos 12d & $5,23 \pm 1,12$ & $5,25 \pm 1,02$ & $\mathrm{NS}^{5}$ \\
Peso $(\mathrm{kg})$ aos $30 \mathrm{~d}^{2}$ & $8,33 \pm 2,06$ & $8,51 \pm 1,94$ & $\mathrm{P}=0,04$ \\
GPD $_{12-20^{3}}$ & 0,120 & 0,142 & \\
GPD $_{20-30}$ & 0,196 & 0,212 & \\
1= peso inicial em kg, antes da aplicação da 1' dose de hormónio (12 dia de idade). \\
2= peso final em kg, após dois dias da aplicação da 2 ${ }^{\mathrm{a}}$ dose do hormônio. \\
3= ganho de peso diário entre 12 e 20 dias de idade \\
4= ganho de peso diário entre 20 e 30 dias de idade \\
5= não significativo estatisticamente. \\
Letras iguais não diferem estatisticamente $(\mathrm{P}>0,10)$.
\end{tabular}

Apesar do aumento no ganho de peso dos cordeiros, não houve diferença $(P=0,74)$ entre os dois tratamentos para a produção de leite (Figura 3). Há que se considerar a acurácia do método utilizado para a quantificação desta produção, que poderia estar subestimando os valores e incorporando variações que não permitiriam detectar a diferença esperada para explicar o melhor desempenho dos cordeiros aleitados pelas ovelhas tratadas com bST.

Diferentemente, Fernandez et al. (1995), verificando o efeito galactopoiético do bST aplicado em ovelhas em lactação em diferentes doses, obtiveram produção de1337 mL/dia no grupo tratado com $160 \mathrm{mg}$ de bST em intervalos de 14 dias, enquanto o grupo controle apresentou produção inferior na ordem de $997 \mathrm{~mL} /$ dia.

Os animais em lactação tiveram uma queda significativa $(P<0,01)$ na produção de leite de 30 a $60 \%$ entre o $12^{\circ}$ e $20^{\circ}$ dia de lactação. Este fato apontaria para o pico de lactação ao redor dos 12 dias de lactação. 


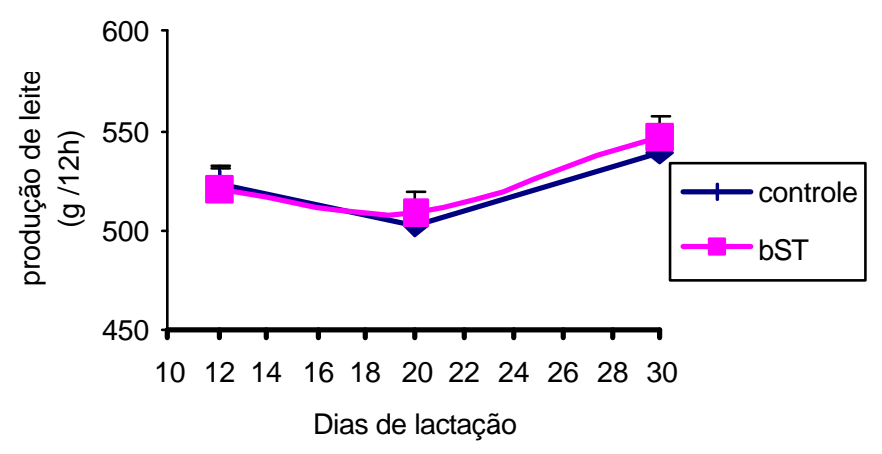

Figura 3 - Médias de produção de leite tomadas pelo método da pesagem do cordeiro.

O pico de lactação das ovelhas, segundo Vernon \& Finley (1985) ocorre entre $013^{\circ}$ e $16^{\circ}$ dia de lactação. Todavia os resultados de produção têm que ser considerados com ressalva, especialmente ao observarmos um aumento na produção entre o $20^{\circ}$ e $30^{\circ}$ dia de lactação retornando aos níveis do $12^{\circ}$ dia.

As concentrações de AGNE medidas no plasma sangüíneo das ovelhas lactantes com ou sem bST não mostraram diferenças significativas $(P>0,05)$, porém houve uma queda sucessiva da concentração nas medições feitas aos 12, 17 e 36 dias de lactação que apresentou efeito significativo $(P<0,01)$ independente do tratamento administrado aos animais (Figura 4).

Embora a ST seja um agente lipolítico, não foi encontrado o esperado efeito do hormônio sobre a mobilização de gordura e o consequentemente aumento da concentração de AGNE no plasma. Nas condições do experimento seria razoável sugerir que a mobilização das reservas estava no seu limiar máximo próximo dos 12 dias pós-parto, coincidindo com o pico da lactação.

Somado ao fato do pico da lactação exercer tamanha demanda, os animais entraram no período experimental com um índice de mobilização de lipídios provavelmente alto decorrente do regime alimentar a pasto até a parição, ou seja, antes da aplicação de quaisquer tratamento. Análises 
através de ultra-sonografia indicaram praticamente a ausência de gordura subcutânea na área de olho de lombo das ovelhas (resultados não publicados). A deficiência energética das ovelhas no período anterior ao experimento pode ter ocasionado um ganho compensatório logo após o parto, quando ocorreu a complementação de um concentrado energético na dieta. As ovelhas ganharam em média $5,5 \pm 1,5 \mathrm{~kg}$ durante um período ( $1^{\mathrm{a}}$ semana) de alta exigência energética para produção de leite.

McCutcheon \& Bauman (1986) utilizando vacas em lactação com balanço energético positivo observaram que não houve diferença no teor de AGNE plasmático entre os grupos tratados ou não com bST in vivo.

$\mathrm{Na}$ comparação das diferentes condições fisiológicas dos animais, não houve diferença estatística $(P>0,05)$ nas concentrações de $A G N E$ no $36^{\circ}$ dia de lactação entre os animais lactantes e os animais secos.

Resultados estes concordam com os de Bauman e Currie (1980) e Vernon e Flint (1984) que verificaram em bovinos e ovinos, respectivamente, que a perda de gordura é maior durante o início da lactação porque as reservas são maiores, e quase metade das reservas de gordura é utilizada durante o terço inicial da lactação. Após este período ocorre um aumento gradual na ingestão de alimentos, o que resulta em uma diminuição da utilização das reservas para a manutenção da lactação. Sabe-se que ST aumenta a resposta a epinefrina e consequentemente aumento da lipólise, mas pode também correr uma influência do balanço de energia nessa resposta (Sechen et al., 1989). 


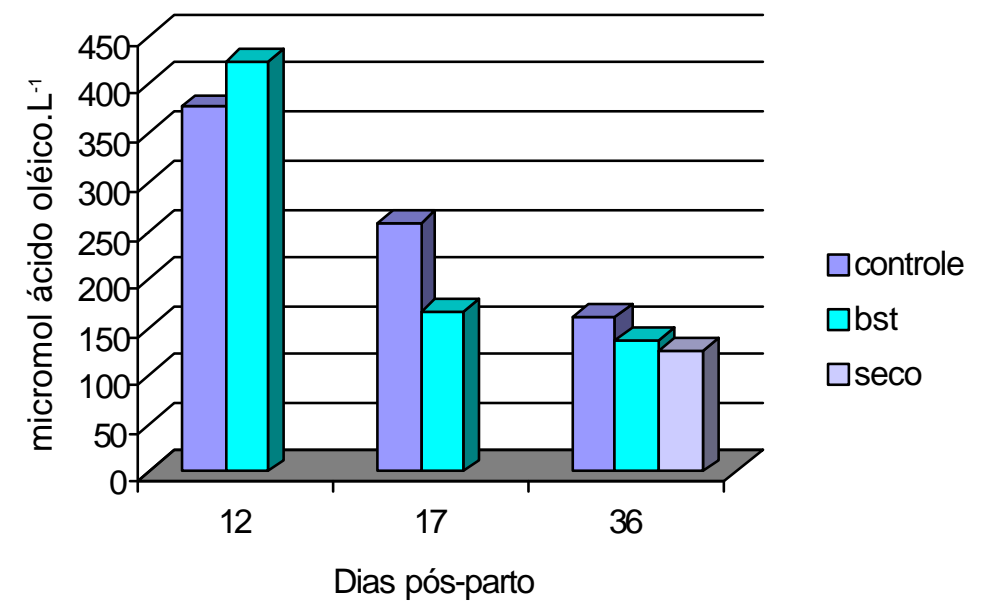

Figura 4 - Liberação de AGNE no plasma sangüíneo das ovelhas dos 3 grupos em diferentes datas pós-parto.

Quanto à concentração de IGF-I no plasma das ovelhas, verificourse que no início da lactação e anteriormente à injeção com bST, aquelas eram semelhantes para os animais designados a ambos os tratamentos (Tabela 4).

Tabela 4. Concentrações médias de IGF-I ( $\mathrm{ng} / \mathrm{mL})$ no plasma sangüíneo em diferentes períodos de coleta.

\begin{tabular}{|c|c|c|c|c|}
\hline $\begin{array}{l}\text { Dias pós- } \\
\text { parto }\end{array}$ & Controle & bST & Seca & $P$ \\
\hline 12 & $233,4^{a}(40,0)$ & $241,4^{a}(47,7)$ & nd & $\mathrm{NS}$ \\
\hline $\begin{array}{c}36 \\
P\end{array}$ & $\begin{array}{c}268,6^{\text {a }}(29,9) \\
N S\end{array}$ & $\begin{array}{c}332,9^{b}(32,1) \\
N S\end{array}$ & $231,4^{a} \quad(22,2)$ & $P<0,10$ \\
\hline $\begin{array}{l}\text { Médias } \\
\text { nd }=\text { nã } \\
N S=\text { nã } \\
\text { Valores } \\
P=\text { prob }\end{array}$ & $\begin{array}{l}\text { uidas por letras igu } \\
\text { terminado } \\
\text { gnificativos estatisti } \\
\text { e parênteses repre } \\
\text { dade. }\end{array}$ & $\begin{array}{l}\text { não diferem estatis } \\
\text { nente } \\
\text { tam coeficiente de }\end{array}$ & ação (\%) & \\
\hline
\end{tabular}


A idéia de que o IGF-I é importante para a lactação surgiu dos estudos com ST, tendo em muitos deles que a administração de ST exógena aumenta a quantidade de somatomedinas (IGF-I) no sangue (Juskevich \& Guyer, 1990; McLaughlin et al., 1993; Hossner et al., 1997; Cohick, 1998). Em estágio mais avançado da lactação (36 dias pós-parto) observamos concentrações plasmáticas de IGF-I significativamente mais elevadas $(P<0,10)$ para os animais que receberam bST em relação às ovelhas em estado seco. Não foram verificadas diferenças entre animais lactantes controle e secos, assim como entre lactantes controle e tratados com bST. E ainda, não foram verificadas diferenças dentre as coletas aos 12 e 36 dias para os animais lactando.

Os IGFs são fatores de crescimento polipeptídicos que já estão presentes em concentrações significantes na circulação de ruminantes em lactação (McGuire et al., 1992), contudo a variabilidade dos dados devido à presença de 'outliers' pode ter contribuído para a não observância de diferentes concentrações plasmáticas. Outra possibilidade para a aparente inoperância do bST exógeno sobre a concentração do IGF-I plasmático das ovelhas no estágio inicial da lactação parece ser uma característica fisiológica. Vacas tratadas com bST no início da actação apresentaram uma menor abundância de RNAm de IGF-I no fígado (Sharma et al.,1994), e consequentemente menor síntese desta proteína no orgão que tem maior contribuição para as concentrações plasmáticas deste fator de crescimento.

A taxa de lipólise basal in vitro verificada pela liberação de AGNE no meio de incubação não foi alterada $(P>0,05)$ com a lactação e o tratamento in vivo com bST (Tabela 6). Da mesma maneira, Vernon \& Finley (1985) utilizando ovelhas em diferentes estados fisiológicos e também em diferentes períodos de lactação verificaram que a taxa basal de lipólise in vitro não foi alterada em tecido adiposo. 
Tabela 5: Efeitos do tratamento crônico com somatotropina bovina in vivo nas taxas de lipólise in vitro dos explantes de tecido adiposo do omento de ovelhas.

\begin{tabular}{ccccc}
\hline $\begin{array}{c}\text { Adição no meio } \\
\text { de incubação }\end{array}$ & Seco & Controle & BST & Probabilidade \\
\hline Basal $^{2}$ & $1,32^{\mathrm{a}}(1,0)$ & $1,51^{\mathrm{a}}(0,7)$ & $1,60^{\mathrm{a}}(0,6)$ & NS \\
ISO $^{3}$ & $3,47^{\mathrm{b}}(3,0)$ & $3,02^{\mathrm{b}}(1,3)$ & $4,25^{\mathrm{c}}(1,6)$ & $<0,01$ \\
ADA $^{4}$ & $1,96^{\mathrm{a}}(1,2)$ & $3,02^{\mathrm{b}}(1,7)$ & $2,55^{\mathrm{d}}(1,6)$ & $<0,01$ \\
ISO $^{\text {ADA }}$ AD $^{5}$ & $5,85^{\mathrm{e}}(2,5)$ & $5,64^{\mathrm{e}}(1,9)$ & $6,25^{\mathrm{f}}(2,1)$ & $<0,01$ \\
Probabilidade & $<0,01$ & $<0,01$ & $<0,01$ &
\end{tabular}

a, b, c d, e, f Médias seguidas de letras diferentes na mesma linha ou coluna diferem estatisticamente $(P<0,01)$.

1 Meio de lipólise adicionados de diferentes fatores

2 Sem adição de nenhum fator ao meio de lipólise

3 Isoproterenol

4 Adenosina deaminase

5 Isoproterenol mais adenosina deaminase

Valores entre parênteses indicam desvio padrão da média

Quando adicionado isoproterenol ( $\beta$-adrenérgico) ao meio, a taxa de lipólise aumentou para as três condições fisiológicas, sendo que para o grupo lactante tratado com bST foi observada uma taxa $30 \%$ superior $(P<0,01)$ à média da taxa para animais secos e para animais lactantes controle, que não diferiram entre si $(P>0,05)$. No caso de vacas em lactação, Lanna et al. (1995) verificaram que ambas as taxas de lipólise basal e estimulada pelo agonista $\beta$ adrenérgico isoproterenol foram ligeiramente aumentadas no tecido adiposo após tratamento in vivo com bST, todavia as diferenças mostraram-se não significativas. 
Diferentemente, Lanna et al. (1992) haviam observado que em tecido adiposo de vacas lactantes que não recebiam bST exógeno in vivo, ocorria aumento da resposta lipolítica a catecolaminas in vitro, quando comparadas as observações feitas para animais tratados com ST.

A resposta dos adipócitos a adenosina é alterada durante a prenhez e a lactação. Na lactação a maior resposta a adenosina pode ser um mecanismo exercido pra prevenir a exaustão da reserva de lipídeos (Vernon, 1984).

A adição de adenosina deaminase (ADA) ao meio de incubação promoveu um aumento significativo $(\mathrm{P}<0,01)$ da taxa de lipólise em relação a taxa basal no tecido adiposo de ovelhas lactantes, enquanto para o tecido das ovelhas secas não ocorreu tal estímulo (Tabela 6). A elevação da taxa lipolítica pela ADA observada para ovelhas lactantes pode ser explicada pela eliminação do efeito inibitório causado pela adenosina, que seria pronunciado devido à desativação de um número elevado do complexo adenosina-receptor (Vernon \& Finley, 1985).

No trabalho de Vernon et al. (1995), a adição de adenosina deaminase $(0,8 \mu \mathrm{grama} / \mathrm{mL})$ aumentou a taxa da lipólise basal de $10 \pm 2$ para $13 \pm 2 \mathrm{nmol} . \mathrm{h}^{-}$ ${ }^{1} .10^{5}$ células em ovelhas não lactando, e de $9 \pm 2$ para $14 \pm 2$ nmol. $\mathrm{h}^{-1} \cdot 10^{5}$ células em ovelhas lactando.

O incremento causado pela ADA na taxa de liberação de AGNE no meio de incubação em relação à taxa basal foi de $100 \%$ no caso do tecido adiposo de ovelhas lactante controle. A taxa de lipólise no tecido adiposo das ovelhas lactantes tratadas com bST foi também estimulada pela ADA, embora com incremento amenizado na ordem de 59\% em relação à taxa basal. Portanto foi verificada uma taxa lipolítica estimulada por ADA mais elevada para o tecido adiposo de ovelhas lactante controle em relação ì ovelhas tratadas com bST $(\mathrm{P}<0,01)$. O emprego de bST parece alterar a cascata lipolítica a partir do receptor de adenosina, causando algumas modificações que tornam a inibição da lipólise menos efetiva (Houseknecht, 1994; Lanna et al., 1995). Portanto, a eliminação da inibição pela adenosina através da ADA possivelmente foi menos efetiva após o tratamento das ovelhas com bST. 
Por outro lado, Lanna et al. (1992), usando bST in vivo em vacas em lactação, verificou que o tratamento não alterou a taxa máxima de lipólise determinada em incubações com ADA.

No meio em que foi adicionado ISO e ADA, houve uma resposta máxima em termos de taxa de liberação de AGNE. Os tecidos das ovelhas lactantes tratadas com bST submetidos ao meio de incubação com ISO+ADA apresentaram taxa de lipólise mais elevada $(P<0,01)$ comparadas com aquelas obtidas de incubações de tecidos de ovelhas lactantes controle e secas que não diferiram estatisticamente $(P>0,05)$.

A maior resposta à ISO+ADA observada na taxa de lipólise do tecido dos animais tratados com bST ocorreu possivelmente por outras modificações além da alteração no número de receptores $\beta$ adrenérgicos, considerando que o tratamento com ST in vivo ou in vitro, resulta em pequena mudança no número de receptores $\beta$ e $\alpha_{2}$ adrenérgico (Watt et al., 1991; Doris et al., 1994; Doris et al., 1996; Houseknecht et al., 1995b).

Sechen et al. (1989) demonstraram que a $R_{\text {máx }}$ e não a sensibilidade foi alterada em vacas tratadas in vivo com catecolaminas. Em contraste no tratamento in vitro com catecolaminas do tecido adiposo de animais tratados in vivo com ST, as diferenças entre essas respostas são pequenas ou mesmo ausentes (Lanna et al., 1992).

Lanna et al. (1995) relataram não encontrar diferença nas taxas de lipólise estimulada com ISO+ADA para os animais lactantes controle e tratados com bST, sendo os valores de 5.469 e 5.335 nmoles. $3 \mathrm{~h}^{-1} \cdot \mathrm{g}^{-1}$, respectivamente.

Outros estudos prévios tornaram notável que a lactação aumentaria tanto a Rmáx quanto à sensibilidade a agonistas $\beta$ adrenérgicos em tecido adiposo subcutâneo e do omento (Guesnet et al, 1987; Iliou e Dermane, 1987). Todavia, neste experimento não foi observada mudança na resposta máxima à ISO+ADA em tecido adiposo de animais lactantes em comparação aos animais secos. Estes dados são difíceis de explicar considerando o fato daqueles autores relatarem aumento significativo no número de $\beta$ receptores em tecido adiposo do omento de animais lactantes. Além disto, Jaster e Wegner (1981) encontraram uma diminuição na atividade da fosfodiesterase em adipócitos de 
ratas lactantes, que causaria aumento da taxa lipolítica pelo aumento dos níveis de $\mathrm{AMPc}$, independentemente de modificações em nível de receptor.

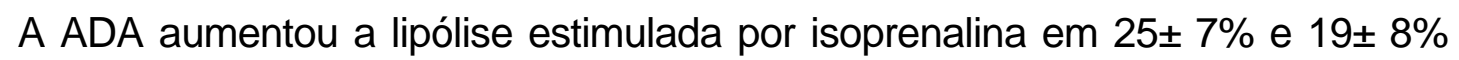
(média \pm DP) em tecido adiposo subcutâneo de ovelhas não lactando e lactando, respectivamente. No entanto, neste trabalho foram verificadas relações com valores distintos aos obtidos no trabalho citado acima, com a contribuição da ADA para a lipólise máxima estimulada por ISO+ADA na ordem de $33,8 \%$ para animais não lactando e $53,5 \%$ para animais lactando controle. E com o uso do bST em animais lactando, obteve-se uma relação de $40 \%$.

Neste estudo, o objetivo também foi elaborar uma curva de dose resposta a PIA em culturas de tecido adiposo do omento de ovelhas secas e lactantes com ou sem tratamento in vivo com bST. As análises de resposta a doses crescentes de PIA, análogo da adenosina detectaram uma ação antilipolítica significativamente reduzida $(P<0,10)$ no tecido adiposo de ovelhas lactantes tratadas com bST (Figura 5) enquanto entre tecidos de ovelhas lactantes controle e secas não houve diferença $(P=0,40)$.

As diferentes concentrações do análogo da adenosina também foram analisadas. A adição 0,5 nM de PIA na cultura de tecido ocasionou uma menor $(P<0,01)$ inibição da taxa lipolítica ou de liberação estimulada de AGNE no meio que doses de 1,5 nM, 3 nM e 100 nM. Entre as doses 1,5 nM e 3,0 nM houve diferença na taxa lipolítica $(P=0,33)$, mas entre 1,5 e $100 \mathrm{nM}$ obteve-se uma diferença $(P=0,03)$. As concentrações de 3 e 100 nM não resultaram em diferenças significativas $(P=0,23)$ na liberação de $A G N E$ no meio de lipólise. Estes resultados são iguais para ambos os tratamentos e também para os diferentes estados fisiológicos.

A dose necessária do análogo da adenosina, PIA, para que houvesse queda da taxa lipolítica estimulada em níveis equivalentes calculados em \% de inibição em relação a taxa máxima estimulada (ISO+ADA), para os diferentes estados fisiológicos deve ser igual a 0,5 nM para animais secos e lactando controle e 1,5 nM para as ovelhas tratadas com bST (Figura 5). Indicando a provável resposta diminuída da cascata da adenosina em tecido adiposo de animais tratados com bST. 


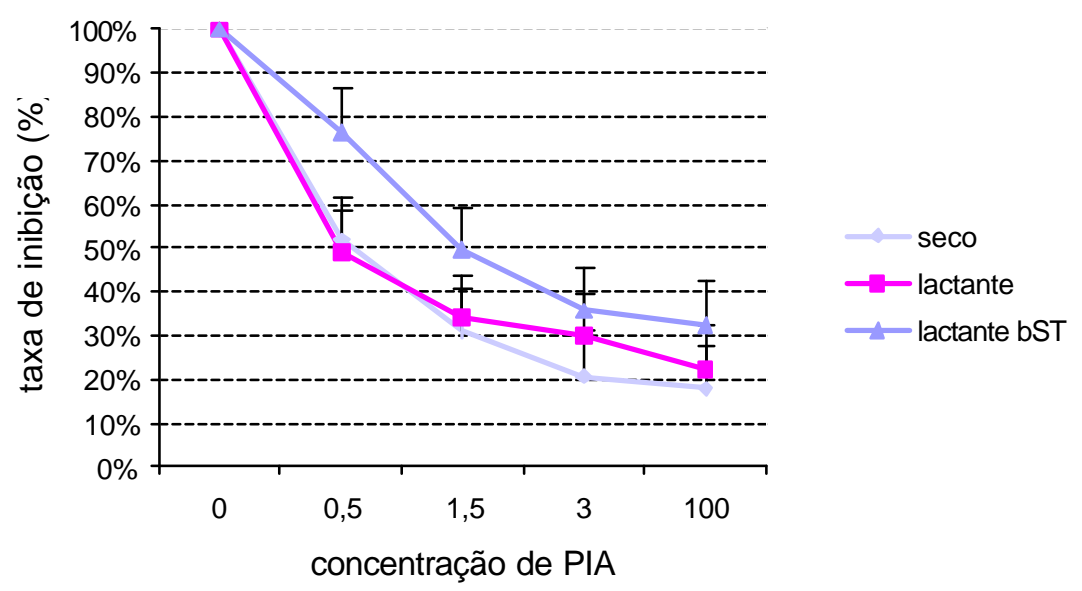

Figura 5 - Inibição da lipólise pelo análogo da ADA, N6-fenilisopropiladenosina (PIA), estimulada por isoproterenol em cultura de tecido adiposo de ovelhas em diferentes fisiológicos.

A lipólise estimulada por isoproterenol foi diminuída quando adicionada PIA ao meio, porém quando usada a concentração de 100nM ocorre uma maior inibição desta lipólise, resultados estes que corroboram aos de Vernon et al., (1995) que verificaram que a lipólise estimulada por isoprenalina foi também diminuída pela presença de 100 nM de PIA em tecido adiposo subcutâneo de ovinos.

A curva da dose resposta de PIA em tecido adiposo humano foi descrita por Ohisalo et al., (1981), e o primeiro efeito parece ser que a PIA diminui a sensibilidade do tecido adiposo ao agonista adrenérgico norepinefrina. No trabalho de Vernon \& Finley (1983) a curva de dose resposta da PIA a várias concentrações de norepinefrina feita com tecido adiposo de ovinos foi bastante semelhante àde Ohisalo et al., (1981).

Vernon \& Finley (1985) ao adicionarem diferentes concentrações de PIA ao meio (2, 20 e $100 \mathrm{nM}$ ) também verificaram diminuição da sensibilidade do tecido ao agonista adrenérgico epinefrina. Quando o tecido adiposo de ovelhas lactando e não lactando foram incubados com $1 \mu$ molar de outro agonista adrenérgico norepinefrina em meios com concentrações crescentes de 
PIA, a taxa de lipólise também foi diminuída. Aqueles autores verificaram que a taxa de lipólise estimulada pela epinefrina variou diretamente com o tamanho do adipócito, e as respostas a epinefrina e a PIA aumentaram durante a lactação.

Segundo Houseknecht e Bauman (1997), a habilidade da adenosina em inibir a lipólise de animais tratados com ST in vivo envolve uma vasta mudança na sensibilidade $\left(E D_{50}\right)$ e uma redução na $R_{\text {máx (ver graf. PIA). Contudo, o }}$ mecanismo não envolve alteração na afinidade das ligações ou número de receptores (Doris et al., 1996, Houseknecht et al., 1995b). Estudos com tecido adiposo de vacas em lactação e ovelhas em crescimento também demonstraram que o tratamento com ST não altera a abundância das subunidades $\alpha, \beta$ ou $\gamma$ ou ainda da proteína heterotrimérica Gi que se ligam a receptores da adenosina (Doris et al., 1996, Houseknecht e Bauman, 1997). 


\section{CONCLUSÃO}

- O tratamento de ovelhas no início da lactação co ST exógena aumentou o ganho de peso destas e também o peso dos cordeiros do grupo tratado ao final do período experimental.

- A concentração plasmática de ácidos graxos não esterificados foi maior no início da lactação (120 dia de lactação).

- Não houve efeito da lactação ou bST exógena sobre a mobilização de gordura, medida pela concentração plasmática de ácidos graxos não esterificados, na fase final da lactação (36 dias pós-parto).

- O uso de bST exógena in vitro aumentou a taxa lipolítica estimulada pelo agonista $\beta$-adrenérgico isoproterenol nos meios de incubação in vitro do tecido adiposo do omento das ovelhas.

- Os tecidos do grupo tratado com bST necessitaram doses mais elevadas do análogo da adenosina PIA para causar diminuição das taxas lipolíticas estimuladas pelo agonista $\beta$-adrenérgico. 


\section{REFERÊNCIAS BIBLIOGRÁFICAS}

ARCH, J. R. S.; NEWSHOLME, E. A. Activities and some properties of 5'nucleotidase, adenosine kinase and adenosine-deaminase in tissues from vertebrates and invertebrates in relation to control of concentration and physiological-role of adenosine. Biochemical Journal, v.174, n.3, p.965977, 1978.

AITCHISON, R. E. D.; CLEGG, R. A.; VERNON, R. G. Lipolysis in rat adipocytes during pregnancy and lactation. The response to noradrenaline. Biochemical Journal, v.202, p.243-247, 1982.

ALENCAR, M. M.; RUZZA, F. J.; PORO, E. J. S. Desempenho produtivo de fêmeas das raças Canchim e Nelore. III. Produção de leite. Revista Brasileira de Zootecnia, v.17, n.4, p.317-328, 1988.

BAUMAN, D. E. Bovine somatotropin and lactation: from basic science to commercial application. Domestic Animal Endocrinology, v.17, p.101116, 1999.

BAUMAN, D. E.; CURRIE, W. B. Partitioning of nutrients during pregnancy and lactation: a review of mechanisms involving homeostasis and homeorhesis. Journal of Dairy Science, v. 63, p.1514-1529, 1980.

BAUMAN, D. E.; ELLIOT, J. M. Control of nutrient partitioning in lactating ruminants. In: METAPHAM, T. B. (Ed.)., Biochemstry of Lactation, Amsterdam: Elsevier, 1983. 437p.

BAUMAN, D.E.; VERNON, R. G. Effects of exogenous bovine somatotropin on lactation. Annual Review of Nutrition. v.13, p.437-461, 1993. 
BAUMAN, D. E.; PEEL, C. J.; STEINHOUR, W. D.; REYNOLDS, P. J.; TYRRELL, H. F.; BROWN, A. C. G.; HAALAND, G. L. Effect of bovine somatotropin on metabolism of lactating dairy cows: influence on rates of irreversible loss and oxidation of glucose and nonesterified fatty acids. Journal of Nutrition, v.118, p.1031-1040, 1988.

BAUMAN, D. E.; DUNSHEA, F. R.; BOISCLAIR, Y. R.; MCGUIRE, M. A.; HARRIS, D. M.; HOUSEKNECHT, K.L. Regulation of nutrient partitioning: homeostasis, homeorhesis and exogenous somatotropin. In: INTERNATIONAL CONFERENCE ON PRODUCTION DISEASE IN FARM ANIMALS. 7., Ithaca, 1989. Proceedings, Ithaca: Cornell University, 1989, p.306-323.

BAXTER, R. C.; MARTIN, J. L.; BENIAC, V. A. High molecular weight insulinlike growth factor binding protein complex. Journal of Biological Chemistry, v.264, p.11843-11848, 1989.

BELL, A. W. Regulation of organic nutrient metabolism during transition from late pregnancy to early lactation. Journal of Animal Science, v.72 (suppl. 1), p.130, 1994.

BERNE, R. M. Adenosine: na important physiological regulator. NIPS, v.1, p.163-167, 1986.

BERNE, R. M.; KNABB, R. M.; ELY, W.; RUBIO,R. Adenosine in the local regulation of blood flow: a brief overview. Federation Proceedings. v.42, n.15, p.3136,1983.

BOISCLAIR, Y. R.; JOHNSTON, K.B.; BAUMAN, D. E.; CROOKER, B. A.; DUNSHEA, F.R.; BELL, A.W. Paradoxical increases of circulating nonesterified fatty acids in somatotropin treated cattle undergoing mild disturbances. Domestic Animal Endocrinology, v.14, n.4, p.251-262, 1997. 
BROWNSEY, R. W.; HARDIE, D. G. Regulation of acetyl-CoA carboxylase identity of sites phosphorylated in intact-cells treated with adrenaline and in vitro by cyclic amp-dependent protein-kinase. FEBS Letters, v.120, n.1, p.67-70, 1980.

BROWNSEY, R. W.; HUGHES, W. A.; DENTON, R. M. Adrenaline and the regulation of acetyl-coenzyme $A$ carboxylase in rat epididymal adipose tissue. Biochemical Journal, v.184, p.23-32, 1979.

BRUNS, .R. F. Adenosine receptor binding assays. Adenosine Receptors. Michigan: Alan R. Liss (Ed.). 1988, p.43-62.

CASTRO, F. C. P. Efeito da somatotropina na quantidade e fosforilação do substrato 1 e 3 do receptor da insulina IRS-1 e IRS-3 e sua associação com a PI 3-quinase. Piracicaba, 2001. 65p. Tese (Mestrado.). Escola Superior de Agricultura "Luiz de Queiroz", Universidade de São Paulo.

COHICK, W. S. Role of insulin-like growth factors and their binding proteins in lactation. Journal of Dairy Science, v.74, p.3421-3428, 1998.

DALY, J. W. Adenosine receptors. In: COOPER, D. M. F.; Seamon, K. B. (ed.). Advances in cyclic nucleotide and protein phosphorylation research. New York: Raven Press, v.19, p.29-46, 1982.

DAUGHADAY, E.; ROLWEIN, P. Insulin-like growth factors I and II. Peptide, messenger ribonucleic acid and gene structures, serum and tissue concentration. Endocrinology Review, v.10, p.68-91,1989.

DELGADO, E. F.; SOUZA, E. P. M., CAMARGO, L. E.; LANNA, D. P. D. Efeito do hormônio do crescimento na expressão gênica da proteína Gi $\alpha-2$ em cultura de tecido adiposo de bovinos. In: REUNIÃO DA SOCIEDADE BRASILEIRA DE ZOOTECNIA, 38., Piracicaba, 2001. Anais. Piracicaba: FEALQ, 2001. p.1304.

DOLE, V. P. Effect of nucleic acid metabolites on lipolysis in adipose tissue. Journal of Biochemical Chemical, v.236, p.3125, 1961. 
DORIS, R. A.; VERNON, R. G.; HOUSLAY, M. D.; KILGOUR, E. Growth hormone decreases the response to anti-lipolytic agonist and decreases the levels of $\mathrm{G}_{\mathrm{i} 2}$ in rat adipocytes. Biochemical Journal, v.297, p.41-45, 1994.

DORIS, R.A.; THOMPSON, G. E.; FINLEY, E.; KILGOUR, E.; HOUSLAY, M. D.; VERNON, R. G. Chronic effects of somatotropin treatment on response of subcutaneous adipose tissue lipolysis to acutely factors in vivo and in vitro. Journal of Animal Science, v.74, p.562-568, 1996.

ETHERTON, T. D.; BAUMAN, D. E. Biology of somatotropin in growth and lactation of domestic animals. Phisiological Reviews, v.78, n.3, p.745-761, 1998.

ETHERTON, T. D.; EVOCK, C. M.; KENSINGER, R. S. Native and recombinant bovine growth hormone antagonize insulin action in cultured bovine adipose tissue. Endocrinology, v.121, n.2, p.699-703, 1987.

EVANS, H. M.; LONG, J. A. Characteristic effects upon growth, oestrus and ovulation induced by intraperitoneal administration of fresh anterior hypophyseal substance. Proceedings of the National Academic Science. v.8, p.38-39. 1921.

FERNANDEZ, N.; RODRIGUEZ, M.; PERIS, C.; BARCELO, M.; MOLINA, M. P.; TORRES, A. Bovine somatotropin dose titration in lactating dairy ewes. 1. Milk yeld and milk composition. Journal of Dairy Science, v.78, p.10731082, 1995.

FERNANDEZ, N.; MOLINA, M. P.; BALASCH, S.; TORRES, A.; ADRIAENS, F. Bovine somatotropin dose titration in lactating dairy ewes. 3. Treatment interval. Journal of Dairy Science, v.84, p.2171-2176, 2001.

GARCIA-SAINZ, A.; FAIN, J. N. Trends Pharmacological Science, v.21, p.201-203, 1982.

GARCIA-SAINZ, J. A ; TORNER, M. L. Rat fat-cells have three types of of types of adenosine receptors (Ra, Ri and P). Biochemical Journal, v.232, p.439443, 1985. 
GEIRSHCHICK, P.; JAKOBS, K. H. The $\boldsymbol{\alpha} 2$ adrenergic receptors. In: LIMBIRD, L. E (Ed.)., Clifton, New Jersey: Human Press, 1988, cap.3, p.75105.

GUESNET, P.; MASSOUD, M.; DEMANNE, Y. Effect of pregnancy and lactation on lipolysis of ewe adipocytes induced by $\beta$ adrenergic stimulation. Mollecular and Cellular Endocrinology, v.50, p.177-181, 1987.

HONNOR, R. C.;. DHILON, G. S.; LONDOS, C. CAMP-dependent protein kinase and lipolysis in rat adipocytes. II. Definition of steady-state relationship with lipolytic and antilipolytic modulators. Journal of Biological Chemistry, v.260, p.15130-15145, 1985.

HOSSNER, K. L.; McCUSKER, R. H.; DODSON, M. V. Insulin like growth factors and their binding proteins in domestic animals. Animal Science, v.64, p.1-15, 1997.

HOUSEKNECHT, K. L.; BAUMAN, D. E. Bovine somatotropin alters pertussis toxin labeling of the inhibitory GTP bindings protein $\left(G_{i}\right)$ in adipose tissue of lactating cows. Journal of Animal Science, v.72, n.1, p.210, (abstract), 1994.

HOUSEKNECHT, K. L.; BAUMAN, D. E. Regulation of lipolysis by somatotropin functional alteration of adrenergic and adenosine signaling in bovine adipose tissue. Journal of Endocrinology, v.152, p.465-475, 1997.

HOUSEKNECHT, K. L.; DWYER, D. A.; LANNA, D. P. D.; BAUMAN, D. E. Effect of somatotropin on adipose tissue metabolism: ontogeny of the enhanced response to adrenergic challenge in the lactating cow. Domestic Animal Endocrinology, v.12, p.105-113, 1995a.

HOUSEKNECHT, K. L.; BAUMAN, D. E.; CAREY, G. B; MERSMANN, H. J. Effect of bovine somatotropin and food deprivation on $\alpha$ adrenergic and $A_{1}$ adenosine receptor binding in adipose tissue of lactating cows. Domestic Animal Endocrinology, v.12, p.325-336, 1995b. 
ILIOU, J. P.; DEMARNE, Y. Evolution of the sensitivity of isolated adipocytes of. International Journal ewes to the lipolytic effects of different stimuli during pregnancy and lactation. Journal of Biochemistry, v.19, n.3, p.253-258, 1987.

JASTER, E. H.; WEGNER, T. N. Beta adrenergic receptor involvement in lipolysis of dairy cattle subcutaneous adipose tissue during dry and lactating state. Journal of Dairy Science, v.64, p.1655-1663, 1981.

JUSKEVICH, J. C.; GUYER, C. G. Bovine Growth Hormone: human food safety evaluation. Science, v.249, p.875-884, 1990.

LANNA, D. P. D.; BAUMAN, D. E. Effect of somatotropin, insulin and glucocorticoid on lipolysis in chronic cultures of adipose tissue from lactating cows. Journal of Dairy Science, v.82, p.60-68, 1999.

LANNA, D. P. D.; DWYER, D. A.; BAUMAN, D. E. Somatotropin and the control of lipogenesis by insulin and adenosine in pig adipose tissue. Journal of Animal Science, v.72, (suppl 1), p.161 (abstract), 1994.

LANNA, D. P. D.; HOUSEKNECHT, K. L; BAUMAN, D. E. Efeito da somatotropina (bST) e $\beta$ adrenérgicos sobre a lipólise e lipase sensível a hormônio em vacas em lactação. Pesquisa Agropecuária Brasileira, v.31 n.1, p.71-77, 1996.

LANNA, D. P. D.; HOUSEKNECHT, K. L.; HARRIS, D. H.; BAUMAN, D. E. Effects of bovine somatotropin on lipolysis, lipogenesis and activities of some enzymes in adipose tissue from lactating cows. Journal of Animal Science, v.70, n.1, p.193, 1992.

LANNA, D. P. D.; HOUSEKNECHT, K. L.; HARRIS, D. H.; BAUMAN, D. E. Efeito do tratamento crônico com somatotropina (bST) na resposta do tecido adiposo de vacas em lactação à ação antilipolítica da insuli na. Revista da Sociedade Brasileira de Zootecnia, v.24, n.5, p.820-831, 1995.

LEFKOWITZ, R. J.; CARON, M. G. Recent Progress Hormonal Research, v.43, p.469-497, 1987. 
LONDOS, C.; COOPER, D. F. M.; WOLF, J. Subclasses of external adenosine receptors. Proceedings of the National Academy Science. v.77, p.25512554. 1980.

MCCUTCHEON, S. N.; BAUMAN, D. E. Effect of chronic growth hormone treatment on responses to epinephrine and thyrotropin-releasing hornome in lactating cows. Journal of Dairy Science, v.64, p.44-51, 1986.

MCGUIRE, M. A.; BAUMAN, D. E.; MILLER, M. A.; HARTNELL, G. F. Response of somatomedins (IGF-I and IGF-II) in lactating cows to variations in dietary energy and protein and treatment with recombinant n-methionyl bovine somatotropin. Journal of Nutrition, v.122, p.128-136, 1992.

McLAUGHLIN, C. L.; HEDRICK, H. B.; VEENHUIZEN J. J.; FINN, R. F. Comparison of performance, clinical chemistry, and carcass characteristics of finishing lambs treated with recombinant ovine or bovine somatotropin. Journal of Animal Science, v.70, p.474-486, 1993.

MCNAMARA, J. P.; HILLERS, J. K. Adaptations in lipid metabolism of bovine adipose tissue in lactogenesis and lactation. Journal of Lipid Research, v.27, p.150-157, 1986.

MCNAMARA, J. P. Regulation of bovine adipose tissue metabolism during lactation. 4. Dose-responsiveness to epinephrine as altered by stage of lactation. Journal of Dairy Science, v.71, p.643-649, 1988.

MCNAMARA, J. P. Regulation of adipose tissue metabolism in support of lactation. Journal of Dairy Science, v.74, p.706-719, 1991.

MILLIGAN, G. Techniques used in the identification and analysis of function of pertussis toxin-sensitive guanine nucleotide binding proteins. Biochemical Journal, v.255, p.1-13, 1988.

NATIONAL ACADEMIC SCIENCE. Desinging foods: Animal product options in the marketplace. National Research Council, Washington, DC: National Academic Science Press. 1988, 156p. 
NATIONAL RESEARCH COUNCIL. Metabolic Modifiers. Effects of nutrient requirements of food-producting animals. Washington, DC: National Academic Science Press. 1994, 243p.

NEER, E.J. Heterotrimeric G proteins: organizers of transmembrane signals. Cell, v.80, p.249-257, 1995.

OHISALO, J. J.; STRANDBERG, H.; KOSTIAINEN, E.; KUUSI, T.; EHNHOLM, C. Stimulation of lipoprotein lipase activity of rat adipose tissue and postheparin plasma by $\mathrm{N}^{6}$-(phenylisopropyl) adenosine. FEBS Letter, v.132, n.1, p.121-123, 1981.

OHISALO, J. J.; STONEHAM, S.; KESO, L. Thyroid status and adenosine content of adipose tissue. Biochemical Journal, v.246, p.555. 1987.

RECHLLER, M. M.; NISSLEY, S. P. Insulin-like Growth Factors. Handbook of Experimental Pharmacology. v.95, p.263-267, 1990.

ROBINSON, G.A.; BUTCHER, R. W.; SUTHERLAND, E. W. In: Cyclic AMP. New York: Academic Press, 1971.

ROBINSON, J. J.; McDONALD, I.; McHATTIE, I.; PENNIE, K. Journal of Agricultural Science, v.91, p.291-304, 1978.

SAS Institute SAS/STAT ${ }^{\text {TM }}$ Guide for personal computers. Cary, SAS Institute, 2000, p.1v.

SCHWABE, U.; EBERT, R; ERBLER, H. C. Adenosine release from isolated fat cells and its significance for the effects of hormones on cyclic 3',5'-AMP levels and lipolysis. Naunyn-Schmiedeberg's Archive Pharmakologie, v.276, n.2, p.133-148, 1973.

SCHWABE, U. Adenosine: Receptors and modulation of cell function. v.625, p.15-28, 1984.

SECHEN, S. J.; MCCUTHEON, S. N.; BAUMAN, D. E. Response to metabolic challenges in early lactation dairy cows during treatment with bovine somatotropin. Domestic Animal Endocrinology, v.6, n.2, p.141-154, 1989. 
SECHEN, S. J.; DUNSHEA F. R.; BAUMAN, D. E. Somatotropin in lactating cows: effect on response to epinephrine and insulin. American Physiology, v.258, n.4,. p.582-587, 1990

SHARMA, B. K.; VANDEHAAR, M. J.; AMES, N. K. Expression of Inslin-Like Growth Factor-I in cows at different stages of lactation and in late lactation cows treated with somatotropin. Journal of Dairy Science, v.77, p.22322241, 1994.

SIDHU, K.S.; EMERY, R.S. Dietary effects on glycerol and fatty-acid mobilization. Journal of Animal Science. v.35, n.5, p.1135, 1972

THIRONE, A. C. P.; CARVALHO; C. R. O.; BRENELLI, S. L.; VELLOSO, L. A.; SAAD, M. J. Effect of chronic hormone treatment on insulin signal transduction in rat tissues. Molecular and Cellular Endocrinology, v.130, p.33-42, 1997.

THOMPSON GE. Vascular and lipolytic responses of the inguinal fat pad of the sheep to adrenergic-stimulation, and the effects of denervation and autotransplantation. quarterly journal of experimental physiology and cognate. Medical Sciences, v.71, n.4, p.559-567, 1986.

VAN CALKER, D.; MULLER, M.; HAMPRECHT, B. Adenosine inhibts the accumulation of cyclic AMP in cultured brain cells. Nature, v.276, p.839841. 1978.

VERNON, R. G. Adenosine: a local modulator of adipose tissue metabolism. Review Hannan Research Institute, p.85-94, 1984.

VERNON, R. G.; FLINT, D. J. Adipose tissue: metabolic adaptation during lactation. Symposium of Zoological Society, v.51, p.119-145, 1984.

VERNON, R. G.; FINLEY, E. Regulation of lipolysis during pregnancy and lactation in sheep. Biochemical Journal, v.230, p.651-656, 1985.

VERNON, R. G.; FINLEY, E. Roles of insulin and growth hormone in the adaptations of fatty acid synthesis in white adipose tissue during the lactation cycle in sheep. Biochemical Journal, v.256, p.873-878, 1988. 
VERNON, R. G.; SASAKI, S. Control of responsiveness of tissues to hormones. Physiological aspects of digestion and metabolism in ruminants: In: INTERNATIONAL SYMPOSIUM ON RUMINANT PHYSIOLOGY, 7., New York, 1991. Proceedings, New York: Academic Press, 1991, p.155-182.

VERNON, R. G.; FINLEY, E.; TAYLOR, E. Adenosine and the control of lipolysis in rat adipocytes during pregnancy and lactation. Biochemical Journal, v.216, p.121-128, 1983.

VERNON, R. G.; FINLEY, E; FLINT, D. J. Role of growth hormone in the adaptations of lipolysis in rat adipocytes during recovery from lactation. Biochemical Journal, v.242, p.931-934, 1987.

VERNON, R.G.; FINLEY, E.; WATT, P. W. Adenosine and the control of adrenergic regulation of adipose tissue lipolysis during lactation. Journal of Dairy Science, v.74, p.695-705, 1991.

VERNON, R. G.; DORIS, R.; KILGOUR, E.; THOMPSON G. E. Role and regulation of adenosine action in control of lipolysis. Journal of Animal Science, v.72, (Suppl. 1), p.210, (abstract), 1994.

VERNON, R. G.; DORIS, R.; FINLEY, E.; HOUSLAY, M. D.; KILGOUR, E; LINDSAY-WATT, S. Effects of lactation on the signal transduction systems regulating lipolysis in sheep subcutaneous and omental adipose tissue. Biochemical Journal, v.308, p.291-296, 1995.

WATT, P. W.; FINLEY, E.; CORK, S.; CLEGG R. A.; VERNON R. G. Chronic control of the $\beta$ and $\alpha 2$ adrenergic systems of sheep adipose tissue by growth hormone and insulin. Biochemistry Journal, v.273, p.39-42, 1991.

YANG, Y. T.; BALDWIN, R. L. Lipolysis in isolated cow adipose cells. Journal of Dairy Science, n.3, p.366-374, 1972.

YIP, R. C.; GOODMAN, H. M. Growth hormone and dexamethasone stimulate lipolysis and activate adenylyl cyclase in rat adipocytes by selectively shifting Gi $\alpha 2$ to lower density membrane fractions. Endocrinology, v.140, n.3, p.1219-1227,1999. 


\section{APÊNDICE}

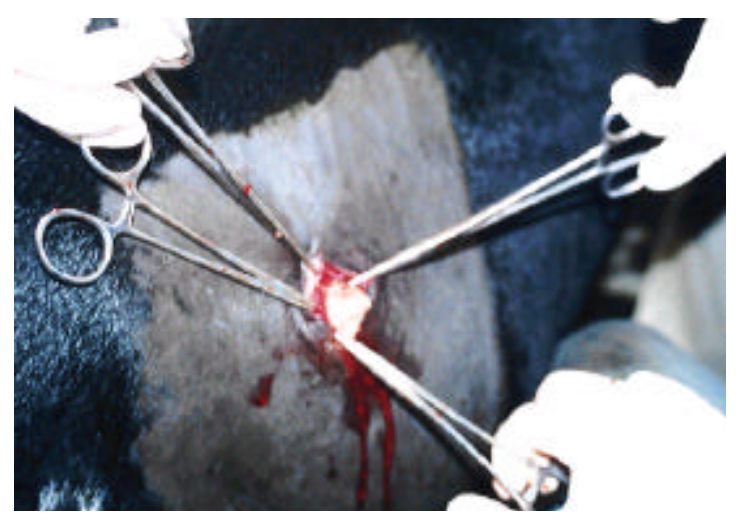

Figura 6 - Abertura do flanco direito para retirada do tecido

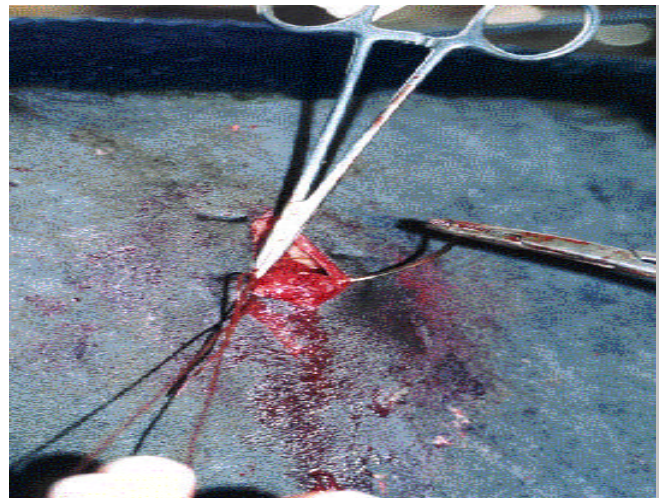

Figura 7 - Sutura do flanco direito (término da biópsia).

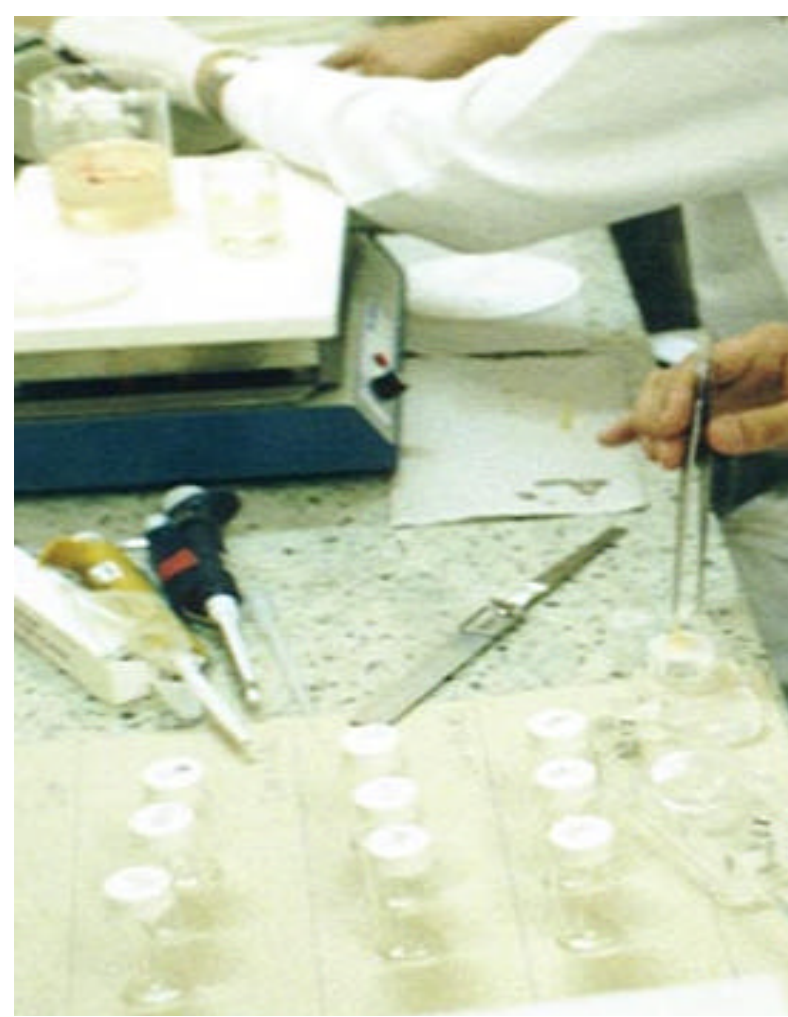

Figura 8 - Preparação do tecido adinnen nara inrı ıharãn

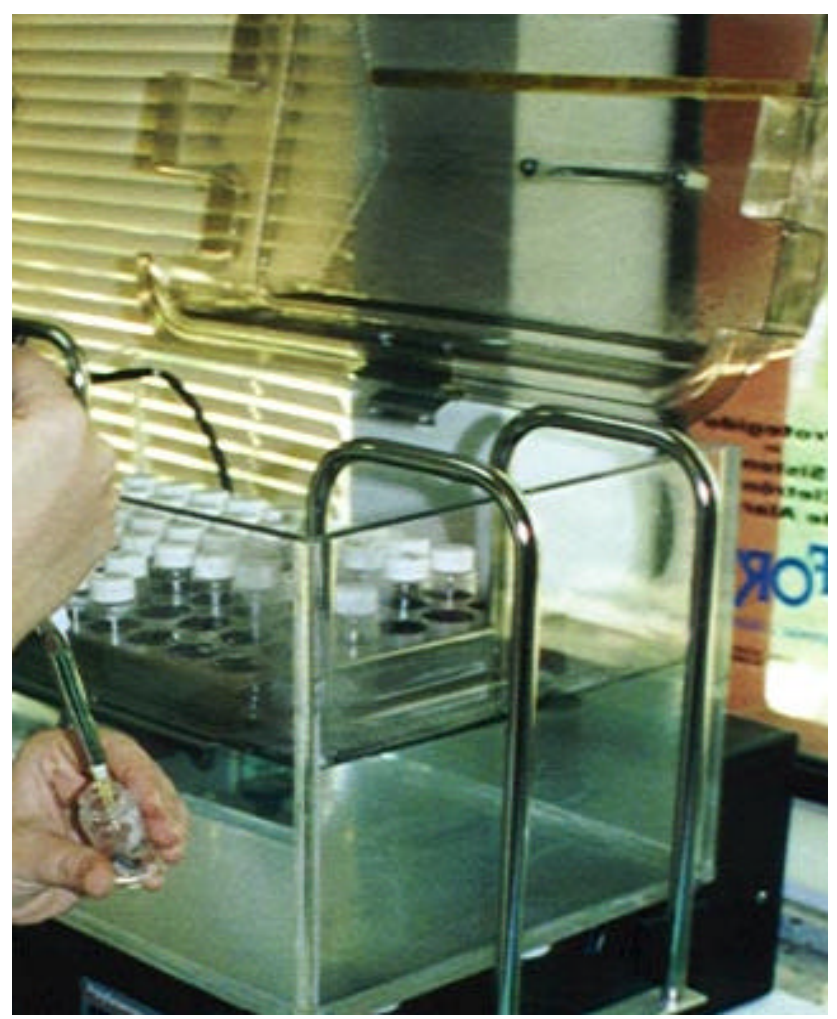

Figura 9 - Coleta de amostra de meio de lipólise durante a cultura do tecido 


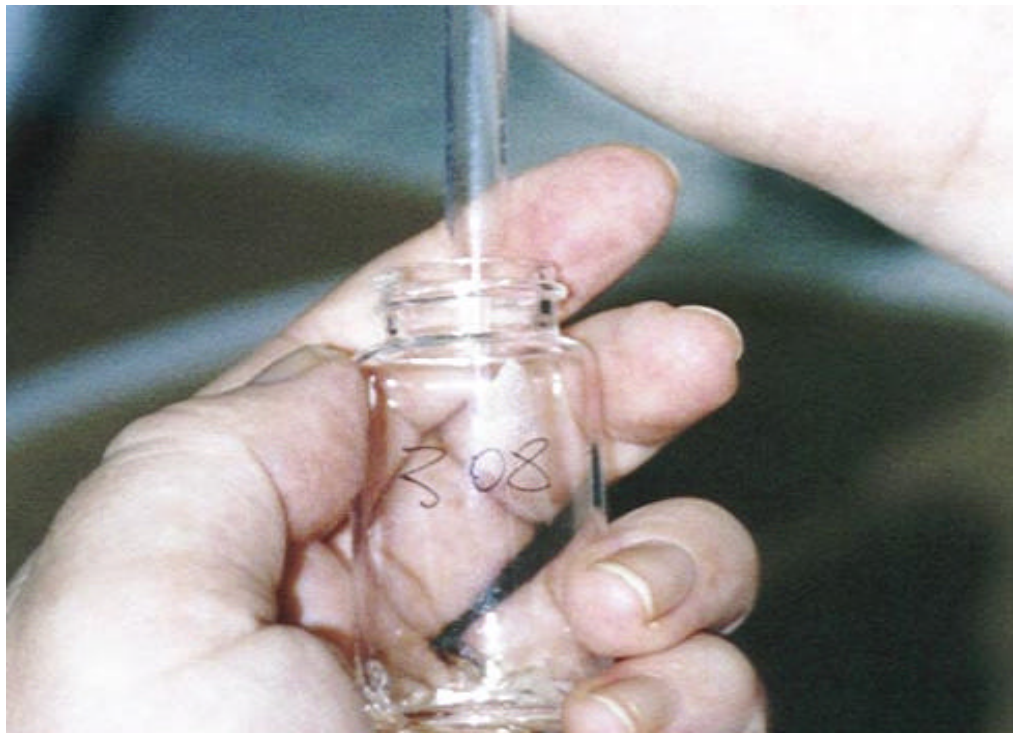

Figura 10 - Colocação da atmosfera de ar $\left(95 \% \mathrm{O}_{2}\right.$ e $5 \% \mathrm{CO}_{2}$ ) no frasco de cintilação durante a incubação. 